\title{
Selective photocatalytic oxidation of aromatic alcohols in water by using P-doped $\mathrm{g}-\mathrm{C}_{3} \mathrm{~N}_{4}$
}

\author{
Marianna Bellardita ${ }^{1}$, Elisa I. García-López ${ }^{1 *}$, Giuseppe Marci ${ }^{1}$, \\ Igor Krivstov $^{2,3}$, José R. García ${ }^{2}$, Leonardo Palmisano ${ }^{1}$ \\ 1 "Schiavello-Grillone" Photocatalysis Group. Dipartimento di Energia, Ingegneria dell'informazione e \\ modelli Matematici (DEIM), Università di Palermo, Viale delle Scienze, 90128 Palermo, Italy. \\ ${ }^{2}$ Department of Organic and Inorganic Chemistry, University of Oviedo-CINN, 33006 Oviedo, Spain. \\ ${ }^{3}$ Nanotechnology Education and Research Center, \\ South Ural State University, 454080, Chelyabinsk, Russia.
}

\begin{abstract}
A set of bare and P-doped graphitic carbon nitride $\left(\mathrm{g}-\mathrm{C}_{3} \mathrm{~N}_{4}\right)$ photocatalysts has been prepared by thermal condensation of melamine, urea or thiourea. For the sake of comparison, a $\mathrm{g}_{-} \mathrm{C}_{3} \mathrm{~N}_{4}$ sample obtained in the presence of cyanuric acid and thermally exfoliated $\mathrm{C}_{3} \mathrm{~N}_{4}$ powders were also studied. The materials were physicochemically characterized and their photocatalytic activity was studied for the selective oxidation of benzyl alcohol (BA), 4-methoxy benzyl alcohol (4-MBA) and piperonyl alcohol (PA) in water suspension both under UV and visible light irradiation. The influence of the type and position of the substituents on conversion and selectivity to aldehyde was remarkable. The presence of $\mathrm{P}$ in the $\mathrm{C}_{3} \mathrm{~N}_{4}$ material improved the selectivity of the reaction towards the aldehyde.
\end{abstract}

Keywords $\mathrm{g}-\mathrm{C}_{3} \mathrm{~N}_{4}$; photocatalysis; doped carbon nitride; selective oxidation, aromatic alcohols

\section{Introduction}

Heterogeneous photocatalysis is a technology widely applied to unselectively obtain the complete mineralization of pollutants. However, its feasibility to selectively oxidize and reduce substrates producing higher value chemicals has been recently proved, demonstrating the possibility to use this technology as a green alternative to industrial catalytic oxidation reactions [1]. The selective oxidation of aromatic alcohols to obtain the corresponding aldehydes has been carried out, in some cases with high yields, in the presence of $\mathrm{TiO}_{2}$-based photocatalysts both in organic [2] and in water solvents [3]. The formation of hydroxyl radicals in the presence of UV irradiated $\mathrm{TiO}_{2}$ leads to the mineralization of organic substrates by unselective attack, although the use of an alternative material possessing lower oxidant ability could result a good choice to obtain partially oxidized products. In this context, carbon nitride $\left(\mathrm{C}_{3} \mathrm{~N}_{4}\right)$, a cheap, metal-free and non-toxic material, which is easily prepared, has recently attracted great attention to perform selective photocatalytic oxidations due to its suitable thermodynamic and physicochemical properties. Graphitic carbon nitride (g$\mathrm{C}_{3} \mathrm{~N}_{4}$ ), the most stable polymorph among $\mathrm{C}_{x} \mathrm{~N}_{y}$ species, due to the similar layered structure of graphene, is a polymeric semiconductor which can be considered a breakthrough in the development of sustainable photocatalysts [4]. Notably, it can be activated by UV light and by a fraction of the visible spectrum of the solar irradiation, due to its quite small band gap value (ca. $2.7 \mathrm{eV}$ ). The low oxidant ability of $\mathrm{C}_{3} \mathrm{~N}_{4}$ can be explained by considering the value of the upper edge of its valence band, which is not enough positive to oxidize water to hydroxyl radicals. Moreover, the electronic features and the tuneable structure and morphology of $\mathrm{C}_{3} \mathrm{~N}_{4}$ make possible its successful use in the field of selective photocatalytic oxidation [5], environmental remediation and energy conversion and storage [6].

$\mathrm{C}_{3} \mathrm{~N}_{4}$ has been mainly studied for water photo-splitting, oxidation and dehydrogenation of organic compounds, and reduction of $\mathrm{CO}_{2}$. The highly negative conduction band value is responsible for the strong reduction ability of the photogenerated electrons [7]. Wang et al. used g- $\mathrm{C}_{3} \mathrm{~N}_{4}$ as photocatalyst for the first time, and they observed an efficient $\mathrm{H}_{2}$ production by using visible light [8]. However, the bare $\mathrm{g}-\mathrm{C}_{3} \mathrm{~N}_{4}$ often 
exhibits low photocatalytic efficiency owing to its small specific surface area $\left(2-10 \mathrm{~m}^{2} / \mathrm{g}\right)$, low absorption in the visible region, formation of grain boundary defects leading to fast recombination of charge carrier pairs, and scarce charge mobility, compared to metals and oxides [9]. Consequently, some modifications are needed to improve its photocatalytic activity and for this purpose many strategies have been applied. Among them, morphology modulation, surface functionalization, thickness control, electronic state regulation, and mesoporous development can be cited [10]. Wang et al. summarized several methods to change the band structures of $\mathrm{C}_{3} \mathrm{~N}_{4}$, as for instance doping and copolymerization [11]. Zhou et al. reported the preparation of non-metal doped carbon nitride photocatalysts and their physicochemical properties, together with their photocatalytic performances [12]. Shalom et al. obtained ordered hollow carbon nitride structure from cyanuric acid melamine complex as the precursor [13]. Zhang et al. prepared P-doped $\mathrm{C}_{3} \mathrm{~N}_{4}$ by using dicyandiamide and an ionic liquid or a phosphate salt as the $\mathrm{P}$ source. The $\mathrm{P}$-doping induced a better electric conductivity and an improvement in photocurrent generation [14]. Ran et al. prepared porous P-doped $\mathrm{C}_{3} \mathrm{~N}_{4}$ nanosheets by combining P doping and thermal exfoliation of a bulk material [15]. They observed mid-gap states due to the P-doping which significantly increased the visible light photocatalytic $\mathrm{H}_{2}$-production compared to pristine $\mathrm{C}_{3} \mathrm{~N}_{4}$. Guo et al. used phosphorous acid to prepare P-doped $\mathrm{C}_{3} \mathrm{~N}_{4}$ for the same reaction [16]. P doping caused a band gap energy decrease from 2.67 to $2.55 \mathrm{eV}$, and it was attributed to a less positive value of the upper edge of the valence band which moved from 1.67 to $1.44 \mathrm{eV}$, although the lower edge of the conduction band moved from -1.00 to $-1.11 \mathrm{eV}$. This insight accounted for the photocatalytic $\mathrm{H}_{2}$ evolution rate increase up to seven times under visible light irradiation.

Selective oxidation of alcohols to their corresponding aldehydes with $\mathrm{O}_{2}$ or air is a very important chemical transformation by an industrial point of view, and consequently strong efforts have been made to develop also a wide variety of photocatalysts for these transformations [17-19]. In the present research, some pristine $\mathrm{C}_{3} \mathrm{~N}_{4}$ and $\mathrm{P}$-doped based carbon nitride materials have been prepared by thermal condensation of melamine, urea or thiourea. A $\mathrm{C}_{3} \mathrm{~N}_{4}$ sample in the presence of cyanuric acid, and some thermally exfoliate powders were also prepared. The selective photo-oxidation of three aromatic alcohols, i.e. benzyl alcohol (BA), 4methoxy benzyl alcohol (4-MBA) and piperonyl alcohol (PA) to the corresponding aldehydes was carried out in water by using all of the above materials whose behaviour was compared with two $\mathrm{TiO}_{2}$ samples. The three alcohols were chosen because they bear different substituent groups which can influence conversion and selectivity. Indeed, it has been reported that the presence of a metoxy group in para position (4-methoxy benzyl alcohol versus benzyl alcohol), increased both reaction rate and selectivity to aldehyde when $\mathrm{TiO}_{2}$ was used as the photocatalyst [20]. The further presence of a meta oxy-alkane substituent in the piperonyl alcohol could also have influence. It is worth noting, that the aldehydes obtained from the partial photooxidation of the chosen alcohols, are important intermediates for the synthesis of fine chemicals, pharmaceuticals, and agricultural chemicals. Benzaldehyde (BAL) is employed to confer almond flavour to foods and fragrant products, and sometimes it is used also in cosmetic products. It is also industrially used as the precursor for other organic compounds, from pharmaceuticals to plastic additives. The photocatalytic partial oxidation of benzyl alcohol in water to obtain benzaldehyde has been reported by using $\mathrm{TiO}_{2}[3,21]$ and $\mathrm{C}_{3} \mathrm{~N}_{4}$ based photocatalysts [22-24]. The studies carried out in the presence of $\mathrm{TiO}_{2}$ indicated ca. 38-42 $\%$. selectivity to BAL formation. The maximum selectivity in the presence of $\mathrm{C}_{3} \mathrm{~N}_{4}$ doped with $1 \%$ of $\mathrm{Ru}$ was found to be ca. $72 \%$, but in this case a strong UV LED was used as the irradiation source and the system was continuously purged with argon. 4-Methoxybenzaldehyde (4-MBAD), called also anisaldehyde, obtained by the partial oxidation of 4-methoxybenzyl alcohol (4-MBA), is widely used in the pharmaceutical and perfumery industries. Previous photocatalytic studies carried out in the presence of $\mathrm{TiO}_{2}$ for partial oxidation of 4-MBA to 4-MBAD using water as the solvent, indicated that the selectivity was $60 \%$ [3] or 72 $\%$ [21], depending on the type of $\mathrm{TiO}_{2}$ used. Piperonal, the aldehyde derived from piperonyl alcohol oxidation, is an important intermediate for the production of cosmetic, pharmaceutical and agrochemical compounds. It is prepared by means of oxidation with chromic acid or ozonoysis with isosafrole, which are processes with a strong environmental impact. Piperonal formation by photocatalytic oxidation of piperonyl alcohol has been previously reported in the presence of $\mathrm{TiO}_{2}$ under $\mathrm{UV}$ irradiation [25]. In that case, 
commercial and home-prepared $\mathrm{TiO}_{2}$ samples have been tested and the best selectivity (ca. $35 \%$ ) was obtained by using a home-prepared sample.

\section{Experimental}

\section{Preparation of the photocatalysts}

Melamine, urea and thiourea (Sigma-Aldrich, analysis grade) have been used as the precursors for the g$\mathrm{C}_{3} \mathrm{~N}_{4}$ preparation. Melamine $(10 \mathrm{~g})$, urea $(20 \mathrm{~g})$ or thiourea $(20 \mathrm{~g})$ were heated $\left(2{ }^{\circ} \mathrm{C} \mathrm{min}^{-1}\right)$ in a closed ceramic crucible up to $520^{\circ} \mathrm{C}$ at $3{ }^{\circ} \mathrm{C} \mathrm{min}^{-1}$ and left for $2 \mathrm{~h}$ until they were cooled down obtaining bulk graphitic carbon nitride, labelled as $\mathrm{C}_{3} \mathrm{~N}_{4}-\mathrm{M}, \mathrm{C}_{3} \mathrm{~N}_{4}-\mathrm{U}$ or $\mathrm{C}_{3} \mathrm{~N}_{4}-\mathrm{TU}$, respectively. Phosphorous doped $\mathrm{C}_{3} \mathrm{~N}_{4}$ materials were prepared in the presence of $\mathrm{NH}_{4}\left(\mathrm{H}_{2} \mathrm{PO}_{4}\right)$ by adding slowly $2 \mathrm{~g}$ of $\mathrm{NH}_{4}\left(\mathrm{H}_{2} \mathrm{PO}_{4}\right)$ to aqueous suspensions containing melamine $(10 \mathrm{~g})$, urea $(20 \mathrm{~g})$ or thiourea $(20 \mathrm{~g})$. The final suspension was stirred at room temperature (ca. $25^{\circ} \mathrm{C}$ ) for $1 \mathrm{~h}$ and then heated at $50^{\circ} \mathrm{C}$ until complete dryness. The obtained powders were calcined in a closed ceramic crucible up to $520^{\circ} \mathrm{C}\left(3{ }^{\circ} \mathrm{C} \mathrm{min}{ }^{-1}\right)$ and left for $2 \mathrm{~h}$ until they were cooled down. They were labelled as $\mathrm{C}_{3} \mathrm{~N}_{4}-\mathrm{M}-\mathrm{P}, \mathrm{C}_{3} \mathrm{~N}_{4}-\mathrm{U}-\mathrm{P}$ or $\mathrm{C}_{3} \mathrm{~N}_{4}-\mathrm{TU}-\mathrm{P}$, respectively. A sample was prepared by dissolving $5.1 \mathrm{~g}$ of cyanuric acid in $100 \mathrm{ml}$ of water and by slowly adding $5 \mathrm{~g}$ of melamine. The resulting white suspension was stirred for $1 \mathrm{~h}$ and then heated up to ca. $50^{\circ} \mathrm{C}$ until complete dryness. The sample, obtained by means of the same thermal treatment above reported for the bare and P-doped $\mathrm{C}_{3} \mathrm{~N}_{4}$ samples, was labelled as $\mathrm{C}_{3} \mathrm{~N}_{4}-\mathrm{M}-\mathrm{CyA}$. Moreover, two thermo-exfoliated carbon nitride samples were also prepared by spreading $\mathrm{C}_{3} \mathrm{~N}_{4}-\mathrm{M}(6 \mathrm{~g})$ on the bottom of a ceramic bowl. Subsequently, a calcination was performed in static air atmosphere from 25 to $520{ }^{\circ} \mathrm{C}$ at 2 or $3{ }^{\circ} \mathrm{C} \mathrm{min}^{-1}$, hence the temperature was maintained for $4 \mathrm{~h}$ at $520^{\circ} \mathrm{C}$. The samples were labelled as $\mathrm{C}_{3} \mathrm{~N}_{4}$-TE-2 and $\mathrm{C}_{3} \mathrm{~N}_{4}$-TE-3, respectively. Commercial $\mathrm{TiO}_{2}$ Evonik P25 and a home prepared $\mathrm{TiO}_{2}$ sample were also used for the sake of comparison. In a previous paper, we have reported that $\mathrm{TiO}_{2}$ prepared from $\mathrm{TiCl}_{4}$ was particularly effective for selective oxidation reactions [25]. This powder was prepared by adding $10 \mathrm{~mL}$ of $\mathrm{TiCl}_{4}$ to $500 \mathrm{~mL}$ of water under vigorous stirring. The resulting solution was stirred for $1 \mathrm{~h}$ at room temperature and then left to age for 6 days at room temperature. The final solid in the suspension was dialyzed by using a commercial Dialysis Tubing Membrane with MW 12,400 cut-off pores (Aldrich) against $4 \mathrm{~L}$ of water, which was replaced every day for 3 days until obtaining a $\mathrm{pH}=5$ of the permeate. Finally, the solid was recovered by means of a rotavapor at $323 \mathrm{~K}$.

\section{Physicochemical characterization of the materials}

The crystalline phase of the samples was determined at room temperature by powder X-ray diffraction analysis (PXRD) carried out by using a Panalytical Empyrean apparatus, equipped with CuKa radiation source and PixCel1D (tm) detector. Specific surface areas (SSAs) were measured in accordance with the standard Brunauer-Emmet-Teller (BET) method from the nitrogen adsorption data by using a Micromeritics ASAP 2020. Infrared spectra of the samples in $\mathrm{KBr}$ (Aldrich) pellets were recorded with $4 \mathrm{~cm}^{-1}$ resolution and 256 scans by using a FTIR-8400 Shimadzu spectrometer. Diffuse reflectance spectra (DRS) were obtained in air at room temperature in the $250-800 \mathrm{~nm}$ wavelengths range by means of a Shimadzu UV-2401 $\mathrm{PC}$ spectrophotometer, with $\mathrm{BaSO}_{4}$ as the reference material. The photoluminescence (PL) spectra were recorded by using a standard spectrofluorometer Edinburgh Instruments FLSP920, equipped with a 450W Xe lamp as excitation source (a wavelength of $365 \mathrm{~nm}$ was selected for samples excitation). Mettler Toledo TGA/SDTA851 was used to investigate the thermal decomposition of $\mathrm{g}_{-} \mathrm{C}_{3} \mathrm{~N}_{4}$ under an $\mathrm{O}_{2}$ flow of 50 $\mathrm{mL} \cdot \mathrm{min}^{-1}$ in the temperature range $25-1000{ }^{\circ} \mathrm{C}$. The binding energies of $\mathrm{C}, \mathrm{N}$ and $\mathrm{O}$ in the samples were measured by X-ray Photoelectron Spectroscopy (XPS) by using a SPECS system equipped with a Hemispherical Phoibos analyzer operating in a constant pass energy, using MgKa radiation ( $\mathrm{h} v=1253.6 \mathrm{eV})$. Elemental analysis of the samples was carried out using an EDAX Oxford Instruments attachment to a Jeol JMS-6610LV scanning electron microscope. 
The photocatalytic experiments were carried out by using two different set-ups. In the first one, a Pyrex cylindrical photoreactor (internal diameter: $32 \mathrm{~mm}$, height: $188 \mathrm{~mm}$ ) containing $150 \mathrm{~mL}$ of aqueous suspension was used. The photoreactor was irradiated externally by three Actinic BL TL MINI 15 W/10 Philips fluorescent lamps emitting in the 340-420 wavelengths range with the main emission peak at $365 \mathrm{~nm}$. The lamps were fitted with $3 \mathrm{~cm}$ distance from the reactor axis. The impinging radiation energy in the range 315-400 $\mathrm{nm}$ was measured by a radiometer Delta Ohm DO9721 with an UVA probe and its average value was $2.7 \mathrm{~W} \mathrm{~m}^{-2}$. In the second set-up, an annular Pyrex photoreactor (internal diameter: $36 \mathrm{~mm}$, external diameter: $60 \mathrm{~mm}$ and height: $200 \mathrm{~mm}$ ) containing $150 \mathrm{~mL}$ of aqueous suspension was used. A $100 \mathrm{~W}$ halogen lamp, placed in correspondence of the internal symmetry axis of the reactor, was used as the irradiation source. The average radiation energy impinging the reactor internal wall were ca. $2 \cdot 10^{3} \mathrm{~W} \mathrm{~m}^{-2}$ and ca. $0.5 \mathrm{~W} \mathrm{~m}^{-2}$ in the $450-750 \mathrm{~nm}$ and $315-400 \mathrm{~nm}$ ranges, respectively. During the experiments, both reactors were open, and the equilibrium between dissolved $\mathrm{O}_{2}$ in the aqueous suspension and in the atmosphere was achieved. The reaction was carried out at ca. $25^{\circ} \mathrm{C}$ as the reactors were provided by a thimble where water was allowed to circulate. Benzyl alcohol (BA), 4-methoxy benzyl alcohol (4-MBA) and piperonyl alcohol (PA) were used as the substrates, and their initial concentration in water was $0.5 \mathrm{mM}$ at natural $\mathrm{pH}$. Before starting the irradiation, $50 \mathrm{mg}$ of catalyst $\left(0.33 \mathrm{~g} \mathrm{~L}^{-1}\right)$ were added to the solution and the obtained suspension was kept in an ultrasonic bath for $10 \mathrm{~min}$ and stirred under dark for $30 \mathrm{~min}$, to attain the adsorption equilibrium. In both set-ups all the photons emitted by the lamp in the range 315-400 nm were absorbed by the suspension. Throughout the reaction, samples of the irradiated suspension were withdrawn every 30 minutes and filtered through $0.25 \mu \mathrm{m}$ membranes (HA, Millipore) to separate the photocatalyst particles before the HPLC analyses. A Beckman coulter HPLC apparatus equipped with a Diode Array detector was used to identify and to determine the concentrations of the substrate and the intermediates. A Phenomenex KINETEK $5 \mu \mathrm{m} \mathrm{C} 18$ column was used, and the eluent $\left(0.8 \mathrm{~mL} \mathrm{~min}^{-1}\right)$ consisted of a mixture of acetonitrile and $13 \mathrm{mM}$ trifluoroacetic acid (20:80 v:v). Standards purchased from Sigma-Aldrich with a purity $>99 \%$ were used to identify the products and to obtain the calibration curves.

\section{Results and discussion}

\section{Characterization of the powders}

The PXRD patterns of all of the graphitic $\mathrm{C}_{3} \mathrm{~N}_{4}$ samples, reported in Figure 1, show the presence of only g$\mathrm{C}_{3} \mathrm{~N}_{4}$ phase for bare and $\mathrm{P}$-doped samples, indicating that the precursors are completely condensed and no crystalline impurities of phosphates are present. The intensity of the diffraction maxima measured for the Pdoped samples is lower with respect to the bare samples. This behaviour has been generally observed for exfoliated $\mathrm{g}-\mathrm{C}_{3} \mathrm{~N}_{4}$ materials, although we have noticed that in this case the disorder provoked by P-doping is not accompanied by exfoliation. One can notice the significant decrease of the peak intensity at $12.6^{\circ}$ corresponding to (100) plane, probably evidencing a lower crystallinity degree compared to the bare g- $\mathrm{C}_{3} \mathrm{~N}_{4}$. The position of the peak at $27^{\circ}$ assigned to (002) plane barely changes with doping, indicating that the interplanar distance in the carbon nitride samples is not affected by the presence of $P$. This is in accordance with the study of Hu et. al who only observed the (002) peak shift for the P-doped carbon nitride samples prepared using ionic liquid as the phosphorous source [26].

\section{FIGURE 1. XRD.}

FTIR spectra of all of the solids reported in Figure 2, confirming the carbon nitride structure of the materials, showed no significant differences among the samples. The broad group of peaks ranging from 3500 to 3000 $\mathrm{cm}^{-1}$ can be attributed to $\mathrm{O}-\mathrm{H}$ and N-H stretching bands, due to the presence of hydroxyl adsorbed species and free amino groups on the surface [27-29]. The strong absorption bands in the range 1650 to $1200 \mathrm{~cm}^{-1}$ are typical stretching vibrations modes of the heptazine heterocyclic $\operatorname{ring}\left(\mathrm{C}_{6} \mathrm{~N}_{7}\right)$ units [30]. The absorption 
band at $1632 \mathrm{~cm}^{-1}$ is attributed to C-N stretching, while at $1560 \mathrm{~cm}^{-1}$ and $1410 \mathrm{~cm}^{-1}$ are typical stretching vibration modes of C-N heterocycles [31-33]. The bands at $1325 \mathrm{~cm}^{-1}$ and $1250 \mathrm{~cm}^{-1}$ are attributed to the stretching vibration of C-NH-C units. The absorption at 887 and $804 \mathrm{~cm}^{-1}$ correspond to the N-H deformation and bending modes of the triazine units, respectively [34]. For the $\mathrm{P}$ containing samples the appearance of a wide band near $978 \mathrm{~cm}^{-1}$ can be attributed to the stretching P-O-P of a phosphate [35]. The phosphate presence cannot be confirmed by the $\mathrm{P}=\mathrm{O}$ stretching which is in the same range of the heptazine stretching modes. The poor resolution of this band can be explained by the contribution attributed to the stretching P-N (at $950 \mathrm{~cm}^{-1}$ ) as reported by $\mathrm{Hu}$ in analogous spectra [26]. Even if the P-C-N stretching would also appear in the range $1110-920 \mathrm{~cm}^{-1}$ we have to exclude it because no additional band appears at ca. 700 $\mathrm{cm}^{-1}$ [36]. A further new band at ca. $490 \mathrm{~cm}^{-1}$ is present in the samples containing P. In the $\mathrm{C}_{3} \mathrm{~N}_{4}-\mathrm{M}-\mathrm{P}$ sample, the band at $486 \mathrm{~cm}^{-1}$ is very weak (Fig. 2 (A)) and its intensity increases in the spectra of $\mathrm{C}_{3} \mathrm{~N}_{4}-\mathrm{U}-\mathrm{P}$ $\left(492 \mathrm{~cm}^{-1}\right)$ and $\mathrm{C}_{3} \mathrm{~N}_{4}$-TU-P $\left(490 \mathrm{~cm}^{-1}\right)$ samples. This band can be assigned to P-O-P bending modes [35]. In the $\mathrm{C}_{3} \mathrm{~N}_{4}$-TU-P a further contribution to this band appears at $526 \mathrm{~cm}^{-1}$ assigned to P-S stretching mode [35]. Notably, the P-S stretching mode is confirmed by the shoulder at ca. $1050-970 \mathrm{~cm}^{-1}$, which can be assigned to the P-S-C stretching [36].

\section{FIGURE 2. FTIR spectra}

The relatively low specific surface areas (SSA) of the $\mathrm{g}-\mathrm{C}_{3} \mathrm{~N}_{4}$ obtained by using thiourea or melamine as the precursors, have been reported in the range $4-7 \mathrm{~m}^{2} \cdot \mathrm{g}^{-1}$, whilst values close to $70 \mathrm{~m}^{2} \cdot \mathrm{g}^{-1}$ have been obtained for samples prepared at high condensation temperatures, although the yields were very low [37]. There are two general ways to increase the SSA of $g-\mathrm{C}_{3} \mathrm{~N}_{4}$, i.e. to carry out the synthesis by hard or soft templating methods or to perform a post-synthetic exfoliation procedure [38]. The SSAs of the $\mathrm{C}_{3} \mathrm{~N}_{4}$ based materials obtained in this research are reported in Table 1. Doping influenced the textural properties of the home prepared $\mathrm{C}_{3} \mathrm{~N}_{4}$ materials depending on the precursors used. SSA values obtained for $\mathrm{C}_{3} \mathrm{~N}_{4}-\mathrm{M}-\mathrm{P}$ and $\mathrm{C}_{3} \mathrm{~N}_{4}-\mathrm{U}-\mathrm{P}$ decreased nearly twice with respect to the bare $\mathrm{C}_{3} \mathrm{~N}_{4}-\mathrm{M}$ and $\mathrm{C}_{3} \mathrm{~N}_{4}-\mathrm{U}$ samples, and the form of the hysteresis loops was different as well (Figure $3 \mathrm{~A}, \mathrm{~B}$ ). Unlike the other two samples, the SSA of $\mathrm{C}_{3} \mathrm{~N}_{4}$-TU-P increased ca. 6 times with respect to the bare $\mathrm{g}_{-} \mathrm{C}_{3} \mathrm{~N}_{4}$ material due to the higher volume of the mesopores as shown in Figure $3(\mathrm{C})$. The explanation of this unusual behaviour might be found by comparing the condensation pathways of urea and thiourea. Zhang et al. [39] proposed that the formation of $\mathrm{CO}_{2}$ during urea condensation was responsible for the enhanced SSA of the formed $g_{-} \mathrm{C}_{3} \mathrm{~N}_{4}$, while the formation of $\mathrm{CS}_{2}$ and $\mathrm{H}_{2} \mathrm{~S}$ did not have the same effect on the development of porous structure in case of applying thiourea as a carbon nitride source. We suggest that the reaction of the mentioned by-products with oxygen of the added phosphates at high temperatures might result in the production of volatile gases favouring pores generation during the $\mathrm{C}_{3} \mathrm{~N}_{4}$-TU$\mathrm{P}$ synthesis. Carbon nitride prepared from the melamine-cyanuric acid complex possesses a SSA of $70 \mathrm{~m}^{2} \mathrm{~g}^{-1}$ (Table 1) that is a significantly higher value with respect to those of the other samples. The profile of adsorption-desorption isotherm of $\mathrm{C}_{3} \mathrm{~N}_{4}$-Cya implies a nonporous nature of carbon nitride layers constituting this sample, although a small hysteresis loop present on the adsorption-desorption isotherm indicates the presence of large mesopores corresponding to intersheet voids (Figure 3(D)).

\section{TABLE 1}

FIGURE 3. Adsorption-desorption $\mathrm{N}_{2}$ isotherms

The optical properties of the samples have been investigated by means of UV-Vis diffuse reflectance spectra (DRS) and photoluminescence (PL) measurements. Figure 4 reports the DRS of the samples that show the typical broad absorption band which can be ascribed to the charge transfer process responsible for the intrinsic indirect band gap of $g-\mathrm{C}_{3} \mathrm{~N}_{4}$ [40]. To determine the optical band-gap energies of the different $\mathrm{C}_{3} \mathrm{~N}_{4}$ based materials, the Kubelka-Munk function $\mathrm{F}(\mathrm{R})$ of the DRS corresponding to the absorbance, reported in Figure 4, has been used. The band-gap values, reported in Table 2, were obtained by extrapolating a linear fitting in the Tauc plot [41], i.e. the plot of $(\mathrm{F}(\mathrm{R}) \mathrm{h} v)^{1 / 2} \mathrm{vs}$ incident light energy in eV by considering the 
powders as indirect semiconductors. DRS show some discrepancies in their absorption properties and hence in the bang gap values.

\section{TABLE 2}

\section{FIGURE 4 DRS}

As far as the photoluminescence (PL) results are concerned, very different spectra were obtained for the carbon nitride samples obtained from different sources. Significant quenching of the luminescence was observed for $\mathrm{C}_{3} \mathrm{~N}_{4}-\mathrm{M}-\mathrm{P}$ compared to its bare counterpart (Figure 5). This finding indicates the occurrence of a better charge separation in the P-doped sample. The presence of $\mathrm{P}$ species for all of the samples (with the exception of $\mathrm{C}_{3} \mathrm{~N}_{4}-\mathrm{M}-\mathrm{P}$ sample) did not significantly influence the PL intensity. In particular, the effect of doping on the PL of $\mathrm{C}_{3} \mathrm{~N}_{4}-\mathrm{U}$ was negligible, whilst the intensity of PL of $\mathrm{C}_{3} \mathrm{~N}_{4}$-TU-P sample slightly increased compared to the bare sample (beware of the different intensity scaling of the spectra). As far as the $\mathrm{C}_{3} \mathrm{~N}_{4}$-CyA, $\mathrm{C}_{3} \mathrm{~N}_{4}$-TE-2 and $\mathrm{C}_{3} \mathrm{~N}_{4}$-TE-3 catalysts are concerned, a luminescence quenching was observed with respect to the $\mathrm{C}_{3} \mathrm{~N}_{4}-\mathrm{M}$, and this effect was particularly evident for the latest two samples, due probably to the more highly ordered exfoliated structure that did not favour the recombination of the photoproduced pairs.

FIGURE 5. Photoluminescence spectra of selected samples.

Thermogravimetric (TG) analysis, showed in Figure 6, allowed to determine the quantity of the dopant species. It is clearly seen that the amount of $\mathrm{P}_{2} \mathrm{O}_{5}$ after the combustion of carbon nitride is relatively large estimated to be similar for all of the samples and equal to $24.4,34.2,27.7 \mathrm{wt} \%$ for $\mathrm{C}_{3} \mathrm{~N}_{4}-\mathrm{M}-\mathrm{P}, \mathrm{C}_{3} \mathrm{~N}_{4}-\mathrm{U}-\mathrm{P}$, and $\mathrm{C}_{3} \mathrm{~N}_{4}$-TU-P, respectively. It is also worth mentioning that the presence of phosphorous containing species affects the combustion process of $\mathrm{g}_{-} \mathrm{C}_{3} \mathrm{~N}_{4}$, which is especially clearly seen for $\mathrm{C}_{3} \mathrm{~N}_{4}-\mathrm{U}-\mathrm{P}$ and $\mathrm{C}_{3} \mathrm{~N}_{4}-\mathrm{TU}-\mathrm{P}$. The carbon nitride sample prepared from the melamine-cyanuric acid complex showed a very similar thermal behaviour with respect to $\mathrm{C}_{3} \mathrm{~N}_{4}-\mathrm{M}$ and also to the other un-doped samples (Figure 6(D)).

FIGURE 6.

The presence of $\mathrm{P}$ as dopant is evident also from the XPS analysis. Indeed, the $\mathrm{P}_{2 \mathrm{p}}$ binding energy peaks of P-doped g- $\mathrm{C}_{3} \mathrm{~N}_{4}$ centred at ca. $133.5 \mathrm{eV}$ (133.4-133.6 eV) are typical for a $\mathrm{P}-\mathrm{N}$ coordination [14], indicating the presence of $\mathrm{P}$ incorporated into the $\mathrm{g}-\mathrm{C}_{3} \mathrm{~N}_{4}$ structure (Figure 7(A)). Thus, the phosphorus heteroatom can replace the corner or bay carbon in the structure forming P-N bonding in the doped $\mathrm{C}_{3} \mathrm{~N}_{4}$ or, as reported by $\mathrm{Hu}$ et al. [26], it occupies interstitial positions forming two P-N bonds (see also FTIR results, Figure 2). Moreover, the presence of phosphate or pyrophosphate groups incorporated into the $g-\mathrm{C}_{3} \mathrm{~N}_{4}$ cannot be excluded. The content of phosphorous in the P-doped carbon nitrides is not the same in all of the samples; the lowest XPS surface concentration of $\mathrm{P}$ is observed for $\mathrm{C}_{3} \mathrm{~N}_{4}-\mathrm{M}-\mathrm{P}$, whilst the largest concentration is found in $\mathrm{C}_{3} \mathrm{~N}_{4}$-TU-P sample (Table 3). It is worth mentioning that oxygen content in the $\mathrm{P}$ doped carbon nitrides increased with the increase of $\mathrm{P}$ concentration (Table 3), which is in accordance with the previously discussed FTIR data evidencing the presence of $\mathrm{O}-\mathrm{P}-\mathrm{O}$ bonds. The surface concentration of $\mathrm{P}$ rising in the order $\mathrm{C}_{3} \mathrm{~N}_{4}-\mathrm{M}-\mathrm{P}, \mathrm{C}_{3} \mathrm{~N}_{4}-\mathrm{U}-\mathrm{P}$, to $\mathrm{C}_{3} \mathrm{~N}_{4}$-TU-P coincides with the trend shown by the SSA values. By taking into account that the bulk phosphorous content determined by TG and EDAX techniques is nearly identical for the mentioned samples, one might conclude that more exposed surface results in higher surface to bulk ratio of P-species.

\section{FIGURE 7}

According to $\mathrm{Hu}$ et al. [26], no significant differences have been observed in the XPS peak positions of C and $\mathrm{N}$ after doping (see Figure 7), however it can be affirmed that the presence of the phosphorous source obviously affects certain structural features of $\mathrm{g}-\mathrm{C}_{3} \mathrm{~N}_{4}$. The $\mathrm{N} 2$ to $\mathrm{N} 1$ peak area ratio, where $\mathrm{N} 1$ and $\mathrm{N} 2$ are the nitrogen atoms belonging to $\mathrm{C}-\mathrm{N}=\mathrm{C}$ and $\mathrm{N}-(\mathrm{C})_{3}$ units, respectively, decreased for the $\mathrm{P}$-doped samples 
with respect to the pristine ones (Figure 7(B)-(D), Table 3). This indicates that the presence of $\mathrm{NH}_{4}\left(\mathrm{H}_{2} \mathrm{PO}_{4}\right)$ during the synthesis favours an improved condensation degree of the obtained material. Although the Pdoping provokes certain structural changes in carbon nitride structure, the integration of $\mathrm{P}$ into heptazine units probably accounts for only a small part of phosphorous content present in the samples, while it is mostly found in the surface region. It draws attention that approximately one of 10 nitrogen atoms in the carbon nitrides is present in the form of uncondensed N3 (C-N-H) species (Table 3), which is close the $\mathrm{N}$ to $\mathrm{P}$ ratio established by the EDAX analysis (Table 1). Hence, one may suggest that surface amino-groups of g$\mathrm{C}_{3} \mathrm{~N}_{4}$ are the primary bonding sites for the P-species, as also observed by FTIR analysis. The XPS study of $\mathrm{C}_{3} \mathrm{~N}_{4}$-Cya sample revels the lowest $\mathrm{N} 3$ to $\mathrm{N} 1$ peak area ratio among all the studied materials, which implies that it contains the smallest relative content of uncondensed amino-groups (Table 3, Figure 7(E)).

The study of the XPS signals at low energy allows to determine the level of the valence band (VB) of a semiconductor. Generally the VB of $\mathrm{g}_{-} \mathrm{C}_{3} \mathrm{~N}_{4}$ prepared from dicyanamide has been reported to be ca. $1.4 \mathrm{eV}$ [42], however the choice of the precursor and the introduction of dopant species might affect this value by shifting it in either directions as it was reported earlier by measuring XPS VB region of various $g-\mathrm{C}_{3} \mathrm{~N}_{4}$ [4346]. In the present case the position of the VB of the doped and pristine carbon nitride are found to be almost the same as it is shown in Table 2 and in Figure 8, indicating that doping with $\mathrm{P}$ mainly affects the CB potential of the $\mathrm{C}_{3} \mathrm{~N}_{4}$ based materials. The $\mathrm{CB}$ estimated values are reported in Table 2 .

\section{FIGURE 8}

\section{Photocatalytic activity under UV or under visible light irradiation}

All the $\mathrm{C}_{3} \mathrm{~N}_{4}$ based samples showed to be photoactive both under UV and Vis light irradiation for the photocatalytic partial oxidation of the three tested alcohols. The results obtained for the selective oxidation of benzyl alcohol (BA), 4-methoxy benzyl alcohol (4-MBA) and piperonyl alcohol (PA) in water are reported in Tables 4 and 5 but they are separately discussed in the following sections.

\section{Photocatalytic oxidation of Benzyl alcohol (BA)}

During the BA photocatalytic experiments, benzaldehyde was obtained as the main product and, in some cases, also benzoic acid was found. The conversion of BA and its selectivity to benzaldehyde after $4 \mathrm{~h}$ of reaction in the presence of the $\mathrm{C}_{3} \mathrm{~N}_{4}$ based materials are reported in Table 4.

\section{TABLE 4}

The perusal of Table 4 shows that by irradiating the system with $\mathrm{UV}$ light, the $\mathrm{C}_{3} \mathrm{~N}_{4}-\mathrm{M}, \mathrm{C}_{3} \mathrm{~N}_{4}-\mathrm{U}$ and $\mathrm{C}_{3} \mathrm{~N}_{4}-$ TU samples gave rise to a modest conversion of BA equal to 11,16 and $13 \%$, respectively. The conversion was the highest for the catalyst with the highest SSA. However, the selectivity to benzaldehyde was significantly higher for $\mathrm{C}_{3} \mathrm{~N}_{4}-\mathrm{M}$ and $\mathrm{C}_{3} \mathrm{~N}_{4}-\mathrm{U}$ (ca. $65 \%$ ) than for $\mathrm{C}_{3} \mathrm{~N}_{4}-\mathrm{TU}$ (ca. $38 \%$ ). A selectivity of ca. 35 $\%$ towards the formation of benzoic acid was in any case observed; indicating that the carbon mass balance was fulfilled for the first two photocatalysts. On the contrary, the formation of other unknown intermediates was observed in the presence of $\mathrm{C}_{3} \mathrm{~N}_{4}-\mathrm{TU}$. The analogous P-doped $\mathrm{C}_{3} \mathrm{~N}_{4}$ samples $\left(\mathrm{C}_{3} \mathrm{~N}_{4}-\mathrm{M}-\mathrm{P}, \mathrm{C}_{3} \mathrm{~N}_{4}-\mathrm{U}-\mathrm{P}\right.$ and $\mathrm{C}_{3} \mathrm{~N}_{4}$-TU-P) were less active than the bare materials showing a lower conversion of benzyl alcohol (ca. $8 \%$ ), but they showed a significant increase of selectivity to benzaldehyde (up to ca. $100 \%$ ). Similar behaviour was observed for the $\mathrm{C}_{3} \mathrm{~N}_{4}-\mathrm{M}$-CyA sample, which showed a conversion close to that found for the pristine $\mathrm{C}_{3} \mathrm{~N}_{4}-\mathrm{M}$, but ca. $90 \%$ selectivity to benzaldehyde. The P-doped samples appeared to be less oxidant photocatalysts than the pristine $\mathrm{C}_{3} \mathrm{~N}_{4}$, but more selective towards the formation of the aldehyde. It seems that the presence of $\mathrm{P}$ was able to avoid or to reduce the formation of benzoic acid. For the sake of comparison, the photocatalytic experiments carried out in the presence of thermo-exfoliated $\mathrm{C}_{3} \mathrm{~N}_{4}$ and bare $\mathrm{TiO}_{2}$ powders are reported in Table 5. The $\mathrm{C}_{3} \mathrm{~N}_{4}$-TE powders resulted the most active ones as far as the BA conversion is 
concerned. In particular, in the presence of $\mathrm{C}_{3} \mathrm{~N}_{4}$-TE-2 the conversion and the selectivity to benzaldehyde after $4 \mathrm{~h}$ were 33 and $56 \%$, respectively, but after $2.5 \mathrm{~h}$ the figures were 19 and $77 \%$, respectively; the latter values are very close to those achieved in the presence $\mathrm{C}_{3} \mathrm{~N}_{4}$-TE-3 after $4 \mathrm{~h}$ of irradiation. The PL spectra, indicating a very small pairs recombination, appears in accord with the higher conversion observed also in the presence of the other two alcohols. Notably both $\mathrm{TiO}_{2}$ Degussa P25 and home prepared $\mathrm{TiO}_{2}(\mathrm{HP})$ are poorly active with a low selectivity to benzaldehyde.

\section{TABLE 5}

Tables 4 and 5 report also results obtained under visible light irradiation. As a general consideration, the conversion values were lower for all of the powders, compared with those obtained under UV irradiation. The selectivity to aldehyde decreased by using almost all of the $\mathrm{C}_{3} \mathrm{~N}_{4}$ based photocatalysts with the exception of $\mathrm{C}_{3} \mathrm{~N}_{4}-\mathrm{M}$ and $\mathrm{C}_{3} \mathrm{~N}_{4}$-TE-3 samples for which a slight increase was found, but the presence of $\mathrm{P}$ was not beneficial for all of the samples. However, the results indicate that the $\mathrm{C}_{3} \mathrm{~N}_{4}$ based materials can be used under visible light irradiation quite successfully and their use is more advisable than that of $\mathrm{TiO}_{2}$. By concluding, the presence of $\mathrm{P}$ in the $\mathrm{g}_{-} \mathrm{C}_{3} \mathrm{~N}_{4}$ samples was able to increase the selectivity versus the formation of benzaldehyde under UV irradiation, although the conversion of BA decreased. On the contrary, under visible light irradiation the presence of $\mathrm{P}$ was detrimental for both conversion and selectivity. These facts indicate that the presence of $\mathrm{P}$ reduced the oxidant ability of the pristine $\mathrm{g}-\mathrm{C}_{3} \mathrm{~N}_{4}$. It is known that the formation of superoxide $\mathrm{O}_{2}{ }^{-}$radical species accounts for the oxidant ability of $\mathrm{C}_{3} \mathrm{~N}_{4}$ in the partial oxidation photocatalytic process [37]. The formation of these species is due to trapping of the photoproduced electrons by $\mathrm{O}_{2}$. Indeed, we have previously observed that the formation of the $\mathrm{OH}$ radicals by the well know mechanism reported by using $\mathrm{TiO}_{2}$ as photocatalyst, does not occur in the presence of $\mathrm{C}_{3} \mathrm{~N}_{4}$ because the value of the valence band is not positive enough to oxidize water to hydroxyl radicals [8-11]. In order to explain the reduced oxidant ability of P-doped $\mathrm{C}_{3} \mathrm{~N}_{4}$, it can be hypothesized that phosphorous species in the $\mathrm{C}_{3} \mathrm{~N}_{4}$ framework (see FTIR and XPS studies) were able to trap electrons reducing their availability in the CB and consequently the formation of the superoxide $\mathrm{O}_{2}{ }^{-}$radical species.

\section{Photocatalytic partial oxidation of 4-methoxybenzyl alcohol (4-MBA)}

The conversion of 4-MBA was much higher than that obtained for BA and the selectivity to 4-MBAD was remarkable in any case. The $\mathrm{C}_{3} \mathrm{~N}_{4}$ pristine powders gave rise to a conversion of ca. $50 \%$ (slightly lower by using $\mathrm{C}_{3} \mathrm{~N}_{4}-\mathrm{TU}$ ), as reported in Table 4. Also in this case, the conversion was higher for the photocatalyst with the highest SSA. The P-doped samples gave rise to a lower conversion of the alcohol than the pristine $\mathrm{C}_{3} \mathrm{~N}_{4}$, but the selectivity to aldehyde was generally higher, consequently the P-doped materials can be considered less oxidant photocatalysts than the corresponding bare ones. This behaviour is the same than that observed for BA partial oxidation and a similar explanation can be provided. Notably, in the presence of the $\mathrm{C}_{3} \mathrm{~N}_{4}$-M-CyA photocatalyst both the selectivity to aldehyde and the conversion of 4-MBA increased with respect to the $\mathrm{C}_{3} \mathrm{~N}_{4}-\mathrm{M}$, and the conversion was ca. $40 \%$ higher compared to the bare $\mathrm{C}_{3} \mathrm{~N}_{4}-\mathrm{M}$. As reported in Table 5, the activity of the thermo-exfoliated samples was remarkable. The home prepared $\mathrm{TiO}_{2}$ powder was more active and selective than the commercial $\mathrm{TiO}_{2}$ Degussa $\mathrm{P} 25$, although the results obtained in the presence of the $\mathrm{TiO}_{2}$ photocatalysts were modest in comparison to those obtained with the $\mathrm{C}_{3} \mathrm{~N}_{4}$ based powders. The selectivity to $4-\mathrm{MBAD}$, reported for the $\mathrm{C}_{3} \mathrm{~N}_{4}$-TE-2 sample, was $64 \%$ at $100 \%$ conversion of 4-MBA after $4 \mathrm{~h}$ of UV irradiation. This value could appear not high with respect to those observed for the other samples. However, it is worth noting that the selectivity in the presence of $\mathrm{C}_{3} \mathrm{~N}_{4}$-TE-2 was ca. $100 \%$ after just $2 \mathrm{~h}$ and $35 \%$ conversion. For higher conversion values, the selectivity decreased due to formation of unidentified intermediates, probably derived from a further oxidation of the aldehyde.

By comparing the selectivity to 4-MBAD reached in the presence of the various samples at irradiation times lower than $4 \mathrm{~h}$, a selectivity of $100 \%$ was observed for the $\mathrm{C}_{3} \mathrm{~N}_{4}-\mathrm{TE}-2, \mathrm{C}_{3} \mathrm{~N}_{4}-\mathrm{TE}-3, \mathrm{C}_{3} \mathrm{~N}_{4}$-TU-P and $\mathrm{C}_{3} \mathrm{~N}_{4}-\mathrm{M}-$ 
CyA samples. This value was achieved when the conversion of 4-MBA was ca. $35 \%$, whilst in the presence of the other materials the selectivity values at $35 \%$ of conversion ranged between $80-90 \%$. In the presence of both the $\mathrm{TiO}_{2}$ samples, the selectivity appeared to be low, never reaching the value of $50 \%$.

The conversion in the presence of the pristine $\mathrm{C}_{3} \mathrm{~N}_{4}$ photocatalysts under visible irradiation slightly decreased with respect to that observed under UV light, but the selectivity increased in particular for $\mathrm{C}_{3} \mathrm{~N}_{4}-\mathrm{U}$ and $\mathrm{C}_{3} \mathrm{~N}_{4-}$ TU samples. Moreover, the conversion decreased but the selectivity remained virtually the same by using the $\mathrm{P}$ doped $\mathrm{C}_{3} \mathrm{~N}_{4}$ samples. The $\mathrm{C}_{3} \mathrm{~N}_{4}-\mathrm{M}$-CyA sample was slightly less active but more selective; the same behaviour was observed for the thermo-exfoliated samples $\mathrm{C}_{3} \mathrm{~N}_{4}-\mathrm{TE}-2$ and $\mathrm{C}_{3} \mathrm{~N}_{4}$-TE-3. It can be concluded that the bare $\mathrm{C}_{3} \mathrm{~N}_{4}$ materials were efficient for the 4-MBA photo-oxidation to the corresponding aldehyde also under visible irradiation, with a slightly smaller conversion but an increased selectivity with respect to the UV irradiation. Also in this case the presence of $\mathrm{P}$ did not improve the performance of the pristine powder under visible light irradiation.

To explain the higher conversion of MBA than BA by using the same photocatalyst and experimental conditions, it is necessary to remind that the aromatic alcohols with electron donating substituent groups (EDG) as $-\mathrm{O}^{-} \mathrm{CH}_{3}$ in different positions, show different photocatalytic reactivity and selectivity, at least in the presence of $\mathrm{TiO}_{2}$ [20]. Indeed, the reaction rate and selectivity were dependent not only on the catalyst properties such as crystallinity and hydrophilicity, but also on the kind and position of the substituent groups of the aromatic alcohols [17,20,21]. It is already known that the aromatic alcohols showed selectivity values decreasing with the methoxy-substituent position in the aromatic ring according to the following order: para $>$ ortho $>$ meta. In the presence of two substituent groups, the overall oxidation rate increased while the selectivity decreased [20]. It has been reported that, in the presence of $\mathrm{TiO}_{2}, \mathrm{BA}$ shows photocatalytic reaction rate and selectivity to aldehyde lower than those observed for 4-MBA photooxidation. This result was also observed during the present investigation in the presence of $\mathrm{C}_{3} \mathrm{~N}_{4}$ based photocatalysts. In the presence of the methoxy group in the para position of the benzylalcohol, both conversion and selectivity increased. The inductive and delocalization effects determined by the presence of the methoxy group in the aromatic ring hinder the oxidant attack which would cause substrate mineralization [47]. The EDG methoxy group is an ortho-para orienting group, and its presence in the para position induces the attack by oxidant species to the benzyl group, thus favouring the transformation of alcohol to aldehyde.

\section{Photocatalytic selective oxidation of Piperonyl alcohol (PA)}

As reported in Table 4, $\mathrm{C}_{3} \mathrm{~N}_{4}$ pristine powders gave rise to a conversion of $\mathrm{PA}$ in the range $22-27 \%$. As a general comment, the selectivity was in any case lower compared with that obtained for the partial oxidation of BA and 4-MBA, probably because of the low stability of the penta-atomic ring under oxidant conditions, due to the presence of the methylen-dioxylic group. Selectivity to piperonal was almost the same for all of the pristine $\mathrm{C}_{3} \mathrm{~N}_{4}$ samples (ca. $20 \%$ ). The presence of the $\mathrm{P}$ atom in the $\mathrm{C}_{3} \mathrm{~N}_{4}$ materials did not substantially change the reactivity with the exception of the $\mathrm{C}_{3} \mathrm{~N}_{4}$-TU-P sample, for which the conversion of PA decreased and the selectivity to piperonal increased. Notably, the presence of cyanuric acid in $\mathrm{C}_{3} \mathrm{~N}_{4}-\mathrm{M}-\mathrm{CyA}$ gave rise to an increase in the selectivity to piperonal with respect to the bare $\mathrm{C}_{3} \mathrm{~N}_{4}-\mathrm{M}$ sample, although the conversion of PA was the same. It is worth to notice that both $\mathrm{C}_{3} \mathrm{~N}_{4}-\mathrm{TU}$ and $\mathrm{C}_{3} \mathrm{~N}_{4}-\mathrm{TU}-\mathrm{P}$ showed the highest selectivity, although the conversion was lower. This phenomenon, observed for $\mathrm{C}_{3} \mathrm{~N}_{4}$-TU-P under UV irradiation, is less evident when the other two alcohols were reacted. The thermo-exfoliated $\mathrm{C}_{3} \mathrm{~N}_{4}$-TE-2 and $\mathrm{C}_{3} \mathrm{~N}_{4}$-TE-3 materials (Table 5) gave rise to a higher conversion than the graphitic $\mathrm{C}_{3} \mathrm{~N}_{4}$ powders and the selectivity were among the highest. As far as the $\mathrm{TiO}_{2}$ powders are concerned, it can be observed that their activity was poor in comparison to that observed in the presence of the thermo-exfoliated $\mathrm{C}_{3} \mathrm{~N}_{4}$, although the selectivity was comparable.

The experiments carried out by irradiating the system with a halogen lamp, analogously to what occurred for the other substrates, indicated that the conversion decreased, whilst the selectivity increased. The findings obtained suggest the possibility to exploit visible light for the photoreaction investigated. On the contrary, a 
significant decrease of activity in terms of conversion and selectivity was observed for the thermo-exfoliated samples under visible light irradiation.

Also for the photocatalytic partial oxidation of piperonyl alcohol, the role of the substituent in meta and para position with respect to the alcoholic group of the aromatic ring can be invoked. It has been mentioned above that, at least in the presence of $\mathrm{TiO}_{2}$ as the photocatalyst, in the contemporary presence of two methoxysubstituent groups in meta and para positions, the overall oxidation rate of benzyl alcohol increased whilst the selectivity decreased [20,48]. A similar behaviour has been observed in in this work, as the conversion of piperonylic alcohol (meta and para position in the aromatic ring are substituted) with respect to benzyl alcohol increased under the same experimental conditions and by using the same photocatalysts, but the selectivity decreased dramatically.

It is worth to mention that the reaction rate of piperonyl alcohol decomposition was always higher than the formation rate of piperonal. This results can be explained, in accord with a previous interpretation, by considering that photocatalytic oxidation of PA proceeded at least by two parallel pathways, the first of which gave rise to formation of piperonal and the other one to complete mineralization [48]. This behaviour was observed also for the other substrates when the runs were carried out in the presence of both $\mathrm{TiO}_{2}$ samples. Moreover, for BA degradation runs carried out in the presence of $\mathrm{C}_{3} \mathrm{~N}_{4}$ based catalysts, the disappearance rate of the substrate corresponded to the sum of the formation rates of benzaldehyde and benzoic acid, suggesting also in these cases the occurrence of two parallel reactions. On the contrary, the disappearance rate of the substrates was virtually the same as that of 4-metoxybenzaldehyde formation, throughout the first hours of 4-MBA oxidation runs in the presence of $\mathrm{C}_{3} \mathrm{~N}_{4}$ based catalysts, and this finding suggests the occurrence of only one reaction pathway. 


\section{Conclusions}

Bare and P-doped graphitic carbon nitride $\left(\mathrm{g}-\mathrm{C}_{3} \mathrm{~N}_{4}\right)$ photocatalysts have been prepared by thermal condensation of melamine, urea or thiourea. The materials were physico-chemically characterized and the presence of phosphate was revealed along with the partial inclusion of $\mathrm{P}$ in the $\mathrm{g}_{-} \mathrm{C}_{3} \mathrm{~N}_{4}$ network with no significant differences between the powders deriving from the three precursors. The photocatalytic oxidation of benzyl alcohol (BA), 4-methoxy benzyl alcohol (4-MBA) and piperonyl alcohol (PA) in air and water suspension of the synthesized materials both under UV and visible irradiation was studied. All the g- $\mathrm{C}_{3} \mathrm{~N}_{4}$ powders resulted active and selective towards the formation of the corresponding aromatic aldehydes. In general, the presence of $\mathrm{P}$ improved the selectivity to the aldehyde and slightly decreased the alcohol conversion. This occurred both under UV and visible irradiation. Reactivity results evidenced that the presence of $\mathrm{P}$ in the $\mathrm{C}_{3} \mathrm{~N}_{4}$ framework reduced the oxidant ability of the g- $\mathrm{C}_{3} \mathrm{~N}_{4}$ materials, giving rise to a less pronounced conversion of the alcohols but to a higher selectivity towards the corresponding aldehyde. The experiments carried out under visible light irradiation, instead of UV, indicated once again that the less oxidant the system was, the higher the selectivity accompanied by a decrease in the alcohol conversion. On the other hand, the presence of cyanuric acid during the melamine condensation did not modify the oxidizing ability of the $\mathrm{g}-\mathrm{C}_{3} \mathrm{~N}_{4}$, increasing both the conversion of the alcohol and the selectivity, probably because this material $\left(\mathrm{C}_{3} \mathrm{~N}_{4}-\mathrm{M}-\mathrm{CyA}\right)$ possesses a higher SSA with respect to the bare $\mathrm{C}_{3} \mathrm{~N}_{4}-\mathrm{M}$ sample. The influence of the type and position of the substituent on the conversion and selectivity to aldehyde was remarkable. The feasibility of the partial oxidation reaction, in fact, followed the order 4-MBA $>$ PA $>\mathrm{BA}$, found also before in the presence of $\mathrm{TiO}_{2}$ as the photocatalyst. This finding indicates that the presence of the oxy-substituent in the aromatic ring enables an easier partial photocatalytic oxidation of the aromatic alcohol to aldehyde, also in the presence of the $\mathrm{C}_{3} \mathrm{~N}_{4}$ based material.

\section{Acknowledgements}

University of Oviedo thanks for financial support Spanish MINECO (MAT2013-40950-R, CTQ2014-52956C3-1-R and MAT2016-78155-C2-1-R) grants. I.K. is grateful for financial support of the Ministry of Education and Science of the Russian Federation (grant No 4.9722.2017/8.9) 


\section{References}

[1] D. Friedmann, A. Hakki, H. Kim, W. Choi, D. Bahnemann, Green Chem. 18 (2016) 5391-5411.

[2] J.C. Colmenares, W. Ouyang, M. Ojeda, E. Kuna, O. Chernyayeva, D. Lisovytskiy, S. De, R. Luque, A.

M. Balu, Appl. Catal. B. 183 (2016) 107-112.

[3] L. Palmisano, V. Augugliaro, M. Bellardita, A. Di Paola, E. I. Garcia-Lopez, V. Loddo, G. Marcì, G. Palmisano, S. Yurdakal, ChemSusChem 4, (2011) 1431-1438.

[4] M. Groenewolt and M. Antonietti, Adv. Mater. 17 (2005) 1789-1792.

[5] J.Z. Bloh, R. Marschall, Eur. J.Org Chem (2017) 2085-2094.

[6] J. Zhu, P. Xiao, H. L. Li and S. A. C. Carabineiro, ACS Appl. Mater. Interf. 6 (2014) 1644916465.

[7] X. Li, J. Yu. M. Jaroniek, Chem. Soc. Rev 45 (2016) 2603-2636.

[8] X.C. Wang, K. Maeda, A. Thomas, K. Takanabe, G. Xin, J.M. Carlsson, K. Domen, M. Antonietti, Nat. Mater. 8 (2009) 76-80.

[9] S. Zhang, J. H. Sun, K. Maeda, K. Domen, P. Liu, M. Antonietti, X.Z. Fu, X. C. Wang, Energy Environ. Sci. 4 (2011) 675-678.

[10] W. Chen, T.Y. Liu, T. Huang, X.H. Liu, X.J. Yang, Nanoscale 8 (2016) 3711-3719.

[11] X.C. Wang, S. Blechert, M. Antonietti, ACS Catal. 2 (2012) 1596-1606.

[12] L. Zhou, H. Zhang, H. Sun, S. Liu, M.O. Tade, S. Wang, W. Jin, Catal Sci. Technol. 6 (2016) $7002-$ 7023.

[13] M. Shalom, S. Inal, C. Fettkenhauer, D. Neher, M. Antonietti, J. Am. Chem. Soc. 135 (2013) 71187121.

[14] Y.J. Zhang, T. Mori, J.H. Ye, M. Antonietti, J. Am. Chem. Soc. 132 (2010) 6294-6295.

[15] J.R. Ran, T.Y. Ma, G.P. Gao, X.W. Du, S.Z. Qiao, Energy Environ. Sci. 8 (2015) 3708-3717.

[16] S.E. Guo, Z.P. Deng, M.X. Li, B.J. Jiang, C.G. Tian, Q.J. Pan, H.G. Fu, Angew. Chem. Int. Ed., 55 (2016) 1830-1834.

[17] L. Palmisano, V. Augugliaro, M. Bellardita, A. Di Paola, E. García-López, V. Loddo, G. Marcì, G. Palmisano, S. Yurkadal, ChemSusChem 4 (2011) 1431-1438.

[18] S. Samanta, S. Khilari, D. Pradhan, R. Srivastava, ACS Sustainable Chem. Eng. 5 (2017) 2562-2577.

[19] J. Kou, C. Lu, J. Wang, Y. Chen, Z. Xu, R.S. Varma, Chem. Rev. 117 (2017) 1445-1514.

[20] S. Yurdakal, V. Augugliaro, RSC Adv. 2 (2012) 8375-8380.

[21] V. Augugliaro, T. Caronna, V. Loddo, G. Marcì, G. Palmisano, L. Palmisano, S. Yurdakal, Chem. Eur. J. 14 (2008) 4640-4646.

[22] J. Si, Y. Liu, S. Chang, D. Wu, B. Tian, J. Zhang, Res. Chem. Interm. 43 (2017) 2067-2080.

[23] M.J. Lima, P.B. Tavares, A.M.T. Silva, C.G. Silva, J.L. Faria, Catal. Today, 287 (2017) 70-77.

[24] S. Masashi, M. Shuji, JP Patent 207, 797, 2011.

[25] M. Bellardita, V. Loddo, G. Palmisano, I. Pibiri, L. Palmisano, V. Augugliaro, Applied Catal. B, 144 (2014) 607-613.

[26] S. Hu, L. Ma, J. You, F. Li, Z. Fan, F. Wang, D. Liu, J. Gui, RSC Adv. 4 (2014) 21657-21663.

[27] S.C. Yan, Z.S. Li, Z.G. Zou, Langmuir 25 (2009) 10397-10401.

[28] X.J. Bai, L. Wang, Y.J. Wang, W.Q. Yao, Y.F. Zhu, Appl. Catal. B 152-153 (2014) 262-270.

[29] S.F. Chen, Y.F. Hu, S.G. Meng, X.L. Fu, Appl. Catal. B 150-151 (2014) 564-573.

[30] P. Niu, L. Zhang, G. Liu, H.M. Cheng, Adv. Funct. Mater. 22 (2012) 4763-4770.

[31] Q.H. Liang, Z. Li, X.L. Yu, Z.H. Huang, F.Y. Kang, Q.H. Yang, Adv. Mater. 27 (2015) 4634-4639.

[32] Z.C. Yang, J. Li, F.X. Cheng, Z. Chen, X.P. Dong, J. Alloy Comp. 634 (2015) 215-222.

[33] Y.J. Sun, W.D. Zhang, T. Xiong, Z.W. Zhao, F. Dong, R.Q. Wang, W.K. Ho, J. Colloid Interf. Sci. 418 (2014) 317-325.

[34] F. Dong, Z.W. Zhao, T. Xiong, Z.L. Ni, W.D. Zhang, Y.J. Sun, W.K. Ho, ACS Appl. Mater. Interf. 5 (2013) 11392-11398.

[35] K. Nakamoto, Infra-Red Spectra of Inorganic and Coordination Compounds, Wiley, New York, 1963 
[36] G. Socrates, Infrared and Raman Characteristic Group Frequencies. Tables and Charts, John Wiley and Sons, Chichester, 2001

[37] I.Krivstov, E.I. García-López, G. Marcì, L. Palmisano, Z. Amghouz, J.R. García, S. Ordóñez, E. Díaz, Applied Catal. B 204 (2017) 430-439.[38] Y. Zheng, L. Lin, B. Wang, X. Wang, Angew. Chem. Int. Ed. 54 (2015) 12868-12884.

[39] Y.J. Zhang, A. Thomas, M. Antonietti, X.C. Wang, J. Am. Chem. Soc. 131 (2008) 50-51.

[40] G. Zhang, J. Zhang, M. Zhang, X. Wang, J. Mater. Chem. 22 (2012) 8083

[41] J. Tauc, Mater. Res. Bull. 5 (1970) 37-46.

[42] Y.J. Cui,Z.X. Ding, P. Liu, M. Antonietti, X.Z. Fu, X.C. Wang, Phys. Chem. Chem. Phys. 14 (2012) 1455-1462.

[43] Q. Lin, L. Li, S. Liang, M. Liu, J. Bi, L. Wu, Appl. Catal. B 163 (2015) 135-142.

[44] Z. Zhao, Y. Sun, Q. Luo, F. Dong, H. Li, W.K. Ho, Scientific Reports 5, (2015) 14643.

[45] S. Hu, L. Ma, J. You, F. Li, Z. Fan, G. Lu, D. Liu, J. Gui, Appl. Surf. Sci. 311 (2014) 164-171

[46] S.C. Yan, Z.S. Li, Z.G. Zou, Langmuir, 26 (2010), 3894-3901.

[47] G. Palmisano, M. Addamo, V. Augugliaro, E. García-López, V. Loddo, L. Palmisano, T. Caronna Chem. Commun. 9 (2006) 1012-1014.

[48] V. Augugliaro, T. Caronna, V. Loddo, G. Marcí, G. Palmisano, L. Palmisano, S. Yurdakal, Chem. Eur. J. 14 (2008) 4640-4646.

[49] C. Lucarelli, A. Lolli, A. Giugni, L. Grazia, S. Albonetti, D. Monticelli, A. Vaccari, Applied Catal. B 203 (2017) 314-323. 
TABLE 1. Specific surface area (SSA), mesopore volume (V) and N:P ratios calculated by EDAX for the prepared samples.

\begin{tabular}{|c|c|c|c|}
\hline Samples & SSA $\left[\mathrm{m}^{2} \mathrm{~g}^{-1}\right]$ & $\mathrm{V}\left[\mathrm{cm}^{3} \mathrm{~g}^{-1}\right]$ & $\begin{array}{c}\text { EDAX elemental } \\
\text { composition N:P }\end{array}$ \\
\hline $\mathrm{C}_{3} \mathrm{~N}_{4}-\mathrm{M}$ & 7 & 0.07 & \\
\hline $\mathrm{C}_{3} \mathrm{~N}_{4}-\mathrm{U}$ & 28 & 0.13 & \\
\hline $\mathrm{C}_{3} \mathrm{~N}_{4}-\mathrm{TU}$ & 5 & 0.04 & 12.0 \\
\hline $\mathrm{C}_{3} \mathrm{~N}_{4}-\mathrm{M}-\mathrm{P}$ & 4 & 0.05 & 11.4 \\
\hline $\mathrm{C}_{3} \mathrm{~N}_{4}-\mathrm{U}-\mathrm{P}$ & 16 & 0.10 & 14.3 \\
\hline $\mathrm{C}_{3} \mathrm{~N}_{4}-\mathrm{TU}-\mathrm{P}$ & 28 & 0.20 & \\
\hline $\mathrm{C}_{3} \mathrm{~N}_{4}-\mathrm{M}-\mathrm{CyA}$ & 70 & 0.43 & \\
\hline
\end{tabular}

TABLE 2. Position of valence and conduction bands and bandgap of bare and P-doped carbon nitrides.

\begin{tabular}{|c|c|c|c|}
\hline Samples & VB $[\mathrm{eV}]$ & Egap $[\mathrm{eV}]$ & $\mathrm{CB}[\mathrm{eV}]$ \\
\hline $\mathrm{C}_{3} \mathrm{~N}_{4}-\mathrm{M}$ & 1.49 & 2.75 & -1.26 \\
\hline $\mathrm{C}_{3} \mathrm{~N}_{4}-\mathrm{U}$ & 1.04 & 2.85 & -1.81 \\
\hline $\mathrm{C}_{3} \mathrm{~N}_{4}-\mathrm{TU}$ & 1.41 & $2.80(2.05)$ & -1.39 \\
\hline $\mathrm{C}_{3} \mathrm{~N}_{4}-\mathrm{M}-\mathrm{P}$ & 1.41 & 2.75 & -1.34 \\
\hline $\mathrm{C}_{3} \mathrm{~N}_{4}-\mathrm{U}-\mathrm{P}$ & 1.04 & 2.84 & -1.80 \\
\hline $\mathrm{C}_{3} \mathrm{~N}_{4}-\mathrm{TU}-\mathrm{P}$ & 1.55 & $2.90(2.15)$ & -1.35 \\
\hline $\mathrm{C}_{3} \mathrm{~N}_{4}-\mathrm{M}-\mathrm{CyA}$ & 1.59 & 2.86 & -1.27 \\
\hline
\end{tabular}

TABLE 3. XPS data obtained for bare and P-doped carbon nitrides.

\begin{tabular}{|c|c|c|c|c|}
\hline Samples & XPS Composition & $\begin{array}{c}\mathrm{N} 1: \mathrm{N} 2: \mathrm{N} 3 \\
\text { ratio }\end{array}$ & $\begin{array}{c}\text { P peak } \\
\text { position/HWHM }\end{array}$ & $\begin{array}{c}\text { O peak } \\
\text { position/HWHM }\end{array}$ \\
\hline $\mathrm{C}_{3} \mathrm{~N}_{4}-\mathrm{M}$ & $\mathrm{C}_{39.8} \mathrm{~N}_{56.9} \mathrm{O}_{3.3}$ & $1: 0.21: 0.12$ & - & $531.8 / 1.5027$ \\
\hline $\mathrm{C}_{3} \mathrm{~N}_{4}-\mathrm{U}$ & $\mathrm{C}_{38.1} \mathrm{~N}_{59.7} \mathrm{O}_{2.2}$ & $1: 0.24: 0.07$ & - & $531.4 / 2.374$ \\
\hline $\mathrm{C}_{3} \mathrm{~N}_{4}-\mathrm{TU}$ & $\mathrm{C}_{41.9} \mathrm{~N}_{55.4} \mathrm{O}_{2.7}$ & $1: 0.15: 0.09$ & - & $531.6 / 2.087$ \\
\hline $\mathrm{C}_{3} \mathrm{~N}_{4}-\mathrm{M}-\mathrm{P}$ & $\mathrm{C}_{37} \mathrm{~N}_{52} \mathrm{O}_{7.7} \mathrm{P}_{3.3}$ & $1: 0.2: 0.13$ & $133.6 / 1.226$ & $531.8 / 1.734$ \\
\hline $\mathrm{C}_{3} \mathrm{~N}_{4}-\mathrm{U}-\mathrm{P}$ & $\mathrm{C}_{36} \mathrm{~N}_{53.3} \mathrm{O}_{6.6} \mathrm{P}_{4.1}$ & $1: 0.12: 0.09$ & $133.4 / 1.183$ & $531.4 / 1.820$ \\
\hline $\mathrm{C}_{3} \mathrm{~N}_{4}-\mathrm{TU}-\mathrm{P}$ & $\mathrm{C}_{26.8} \mathrm{~N}_{44.5} \mathrm{O}_{19.5} \mathrm{P}_{9.2}$ & $1: 0.10: 0.08$ & $133.4 / 1.205$ & $531.6 / 1.682$ \\
\hline $\mathrm{C}_{3} \mathrm{~N}_{4}-\mathrm{Cya}$ & $\mathrm{C}_{39.8} \mathrm{~N}_{57.2} \mathrm{O}_{3.0}$ & $1: 0.19: 0.06$ & - & $533.6 / 1.70$ \\
& & & & $536.0 / 1.06$ \\
\hline
\end{tabular}


TABLE 4. Conversion percentage (X) of BA, 4-MBA and PA and selectivity percentage (S) towards the corresponding aldehyde for runs carried out in the presence of $\mathrm{C}_{3} \mathrm{~N}_{4}$ based materials after $4 \mathrm{~h}$ of irradiation.

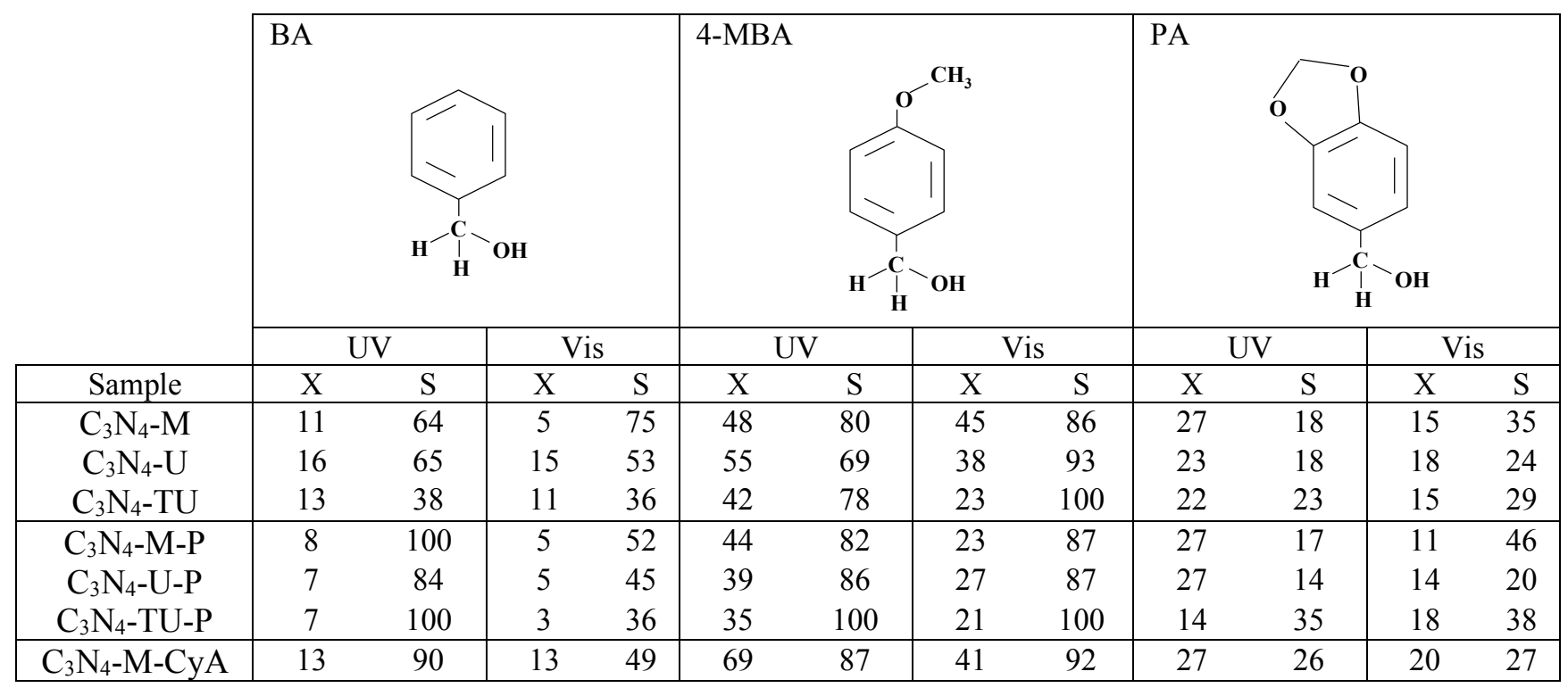

TABLE 5. Conversion percentage (X) of BA, 4-MBA and PA and selectivity percentage (S) towards the corresponding aldehyde for runs carried out in the presence of thermal exfoliated $\mathrm{C}_{3} \mathrm{~N}_{4}$ and $\mathrm{TiO}_{2}$ samples after $4 \mathrm{~h}$ of irradiation.

\begin{tabular}{|c|cc|cc|cc|cc|ccc|c|}
\cline { 2 - 15 } \multicolumn{1}{c|}{} & \multicolumn{4}{c|}{ BA } & \multicolumn{4}{c|}{ 4-MBA } & \multicolumn{4}{c|}{ PA } \\
\cline { 2 - 15 } \multicolumn{1}{c|}{} & \multicolumn{3}{c|}{ UV } & \multicolumn{2}{c|}{ Vis } & \multicolumn{2}{c|}{ UV } & \multicolumn{3}{c|}{ Vis } & UV & Vis \\
\hline Sample & $\mathrm{X}$ & $\mathrm{S}$ & $\mathrm{X}$ & $\mathrm{S}$ & $\mathrm{X}$ & $\mathrm{S}$ & $\mathrm{X}$ & $\mathrm{S}$ & $\mathrm{X}$ & $\mathrm{S}$ & $\mathrm{X}$ & $\mathrm{S}$ \\
\hline $\mathrm{C}_{3} \mathrm{~N}_{4}$-TE-2 & 33 & 56 & 20 & 51 & 100 & 64 & 100 & 72 & 36 & 21 & 25 & 24 \\
$\mathrm{C}_{3} \mathrm{~N}_{4}$-TE-3 & 17 & 69 & 14 & 77 & 91 & 72 & 42 & 84 & 30 & 26 & 10 & 22 \\
\hline $\mathrm{P} 25$ & 15 & 23 & 13 & 12 & 18 & 35 & 18 & 23 & 12 & 21 & 12 & 24 \\
$\mathrm{HP}$ & 7 & 37 & 5 & 23 & 27 & 49 & 20 & 56 & 18 & 22 & 10 & 22 \\
\hline
\end{tabular}




\section{CAPTIONS FOR FIGURES}

Figure 1. PXRD patterns of selected $\mathrm{C}_{3} \mathrm{~N}_{4}$ based home prepared samples: (A) $\mathrm{C}_{3} \mathrm{~N}_{4}$ samples prepared by using melamine as the precursor (a) $\mathrm{C}_{3} \mathrm{~N}_{4}-\mathrm{M}$, (b) $\mathrm{C}_{3} \mathrm{~N}_{4}-\mathrm{M}-\mathrm{P}$; (B) $\mathrm{C}_{3} \mathrm{~N}_{4}$ samples prepared by using urea as the precursor (a) $\mathrm{C}_{3} \mathrm{~N}_{4}-\mathrm{U}$, (b) $\mathrm{C}_{3} \mathrm{~N}_{4}-\mathrm{U}-\mathrm{P}$; (C) $\mathrm{C}_{3} \mathrm{~N}_{4}$ samples prepared by using thiourea as the precursor (a) $\mathrm{C}_{3} \mathrm{~N}_{4}{ }^{-}$ $\mathrm{TU}$, (b) $\mathrm{C}_{3} \mathrm{~N}_{4}$-TU-P; (D) $\mathrm{C}_{3} \mathrm{~N}_{4}-\mathrm{M}-\mathrm{CyA}$.

Figure 2. FTIR spectra of selected $\mathrm{C}_{3} \mathrm{~N}_{4}$ based home prepared samples: (A) $\mathrm{C}_{3} \mathrm{~N}_{4}$ samples prepared by using melamine as the precursor (a) $\mathrm{C}_{3} \mathrm{~N}_{4}-\mathrm{M}$, (b) $\mathrm{C}_{3} \mathrm{~N}_{4}-\mathrm{M}-\mathrm{P}$, (c) $\mathrm{C}_{3} \mathrm{~N}_{4}-\mathrm{M}-\mathrm{CyA}$; (B) $\mathrm{C}_{3} \mathrm{~N}_{4}$ samples prepared by using urea as the precursor (a) $\mathrm{C}_{3} \mathrm{~N}_{4}-\mathrm{U}$, (b) $\mathrm{C}_{3} \mathrm{~N}_{4}-\mathrm{U}-\mathrm{P}$; (C) $\mathrm{C}_{3} \mathrm{~N}_{4}$ samples prepared by using thiourea as the precursor (a) $\mathrm{C}_{3} \mathrm{~N}_{4}-\mathrm{TU}$, (b) $\mathrm{C}_{3} \mathrm{~N}_{4}-\mathrm{TU}-\mathrm{P}$.

Figure 3. Adsorption-desorption $\mathrm{N}_{2}$ isotherms obtained for selected samples: (A) $\mathrm{C}_{3} \mathrm{~N}_{4}$ samples prepared by using melamine as the precursor (a) $\mathrm{C}_{3} \mathrm{~N}_{4}-\mathrm{M}$, (b) $\mathrm{C}_{3} \mathrm{~N}_{4}-\mathrm{M}-\mathrm{P}$; (B) $\mathrm{C}_{3} \mathrm{~N}_{4}$ samples prepared by using urea as the precursor (a) $\mathrm{C}_{3} \mathrm{~N}_{4}-\mathrm{U}$, (b) $\mathrm{C}_{3} \mathrm{~N}_{4}-\mathrm{U}-\mathrm{P}$; (C) $\mathrm{C}_{3} \mathrm{~N}_{4}$ samples prepared by using thiourea as the precursor (a) $\mathrm{C}_{3} \mathrm{~N}_{4}$ TU, (b) $\mathrm{C}_{3} \mathrm{~N}_{4}-\mathrm{TU}-\mathrm{P}$; (D) $\mathrm{C}_{3} \mathrm{~N}_{4}-\mathrm{M}-\mathrm{CyA}$.

Figure 4. DR UV-vis spectra of $\mathrm{C}_{3} \mathrm{~N}_{4}$ samples.

Figure 5. Photoluminescence spectra of some $\mathrm{C}_{3} \mathrm{~N}_{4}$ samples: (A) $\mathrm{C}_{3} \mathrm{~N}_{4}$ samples prepared by using melamine as the precursor (a) $\mathrm{C}_{3} \mathrm{~N}_{4}-\mathrm{M}$, (b) $\mathrm{C}_{3} \mathrm{~N}_{4}-\mathrm{M}-\mathrm{P}$; (B) $\mathrm{C}_{3} \mathrm{~N}_{4}$ samples prepared by using urea as the precursor (a) $\mathrm{C}_{3} \mathrm{~N}_{4}-\mathrm{U}$, (b) $\mathrm{C}_{3} \mathrm{~N}_{4}-\mathrm{U}-\mathrm{P}$; (C) $\mathrm{C}_{3} \mathrm{~N}_{4}$ samples prepared by using thiourea as the precursor (a) $\mathrm{C}_{3} \mathrm{~N}_{4}-\mathrm{TU}$, (b) $\mathrm{C}_{3} \mathrm{~N}_{4}-$ TU-P; (D) (a) $\mathrm{C}_{3} \mathrm{~N}_{4}-\mathrm{M}-\mathrm{CyA}$, (b) $\mathrm{C}_{3} \mathrm{~N}_{4}-\mathrm{TE}-2$, (c) $\mathrm{C}_{3} \mathrm{~N}_{4}-\mathrm{TE}-3$.

Figure 6. TG analysis of selected $\mathrm{C}_{3} \mathrm{~N}_{4}$ samples: (A) $\mathrm{C}_{3} \mathrm{~N}_{4}$ samples prepared by using melamine as the precursor (a) $\mathrm{C}_{3} \mathrm{~N}_{4}-\mathrm{M}$, (b) $\mathrm{C}_{3} \mathrm{~N}_{4}-\mathrm{M}-\mathrm{P}$; (B) $\mathrm{C}_{3} \mathrm{~N}_{4}$ samples prepared by using urea as the precursor (a) $\mathrm{C}_{3} \mathrm{~N}_{4}-\mathrm{U}$, (b) $\mathrm{C}_{3} \mathrm{~N}_{4}-\mathrm{U}-\mathrm{P}$; (C) $\mathrm{C}_{3} \mathrm{~N}_{4}$ samples prepared by using thiourea as the precursor (a) $\mathrm{C}_{3} \mathrm{~N}_{4}-\mathrm{TU}$, (b) $\mathrm{C}_{3} \mathrm{~N}_{4}-\mathrm{TU}-\mathrm{P}$; (D) $\mathrm{C}_{3} \mathrm{~N}_{4}-\mathrm{M}-\mathrm{CyA}$.

Figure 7. XPS spectra of P (fig. A) and N 1s region (figs. B, C, D and E) obtained for selected samples.

Figure 8. Valence band of the carbon nitride samples determined by low energy XPS analyses. (A) $\mathrm{C}_{3} \mathrm{~N}_{4}$ samples prepared by using melamine as the precursor (a) $\mathrm{C}_{3} \mathrm{~N}_{4}-\mathrm{M}$, (b) $\mathrm{C}_{3} \mathrm{~N}_{4}-\mathrm{M}-\mathrm{P}$; (B) $\mathrm{C}_{3} \mathrm{~N}_{4}$ samples prepared by using urea as the precursor (a) $\mathrm{C}_{3} \mathrm{~N}_{4}-\mathrm{U}$, (b) $\mathrm{C}_{3} \mathrm{~N}_{4}-\mathrm{U}-\mathrm{P}$; (C) $\mathrm{C}_{3} \mathrm{~N}_{4}$ samples prepared by using thiourea as the precursor (a) $\mathrm{C}_{3} \mathrm{~N}_{4}-\mathrm{TU}$, (b) $\mathrm{C}_{3} \mathrm{~N}_{4}-\mathrm{TU}-\mathrm{P}$; (D) $\mathrm{C}_{3} \mathrm{~N}_{4}-\mathrm{M}-\mathrm{CyA}$.

Figure 9. SEM images of $\mathrm{C}_{3} \mathrm{~N}_{4}-\mathrm{M}-\mathrm{P}$ sample before $(\mathrm{A}-\mathrm{C})$ and after four photocatalytic cycles (D-F) at different enlargements. 


\section{Figures}
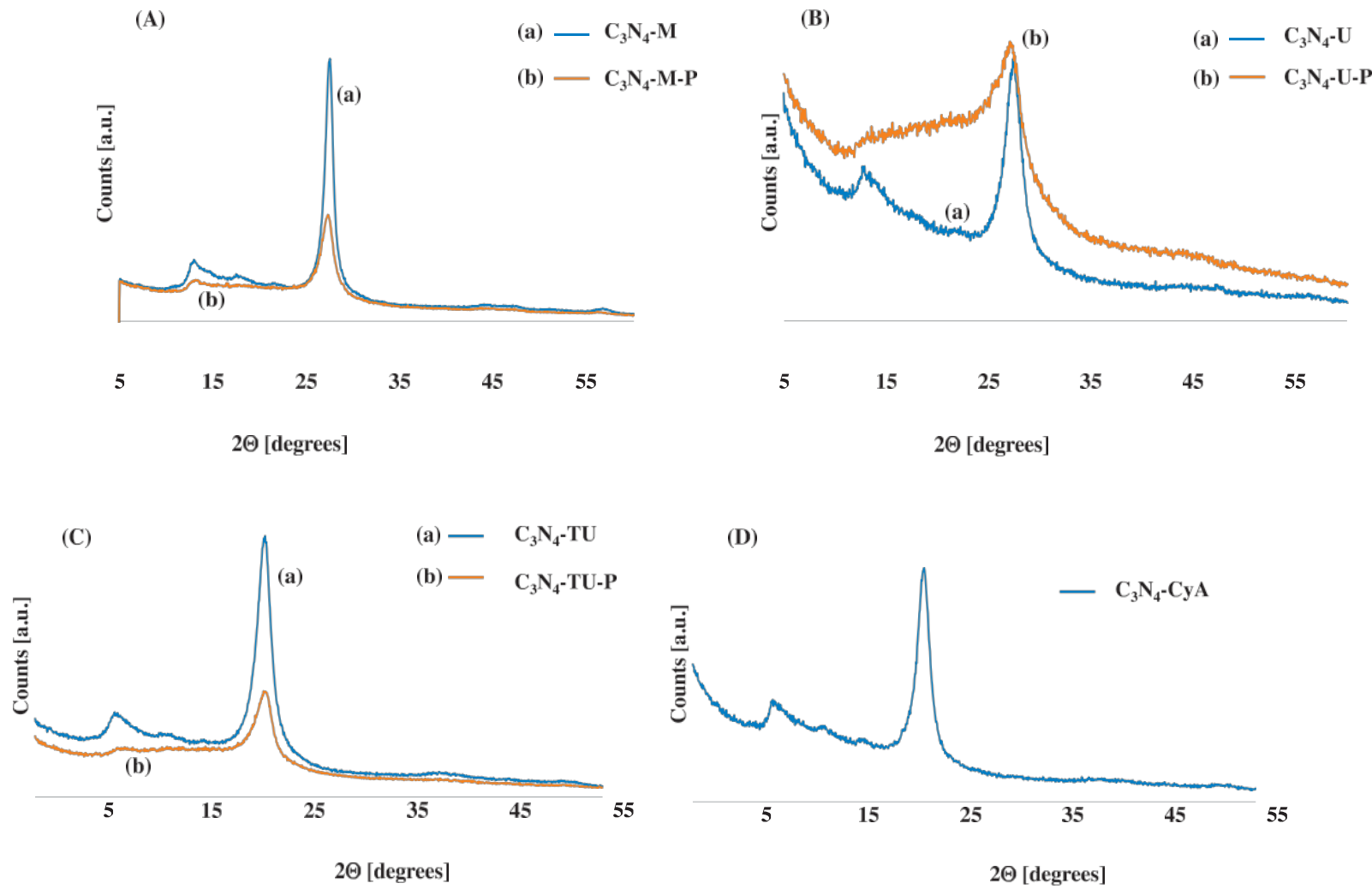

(D)

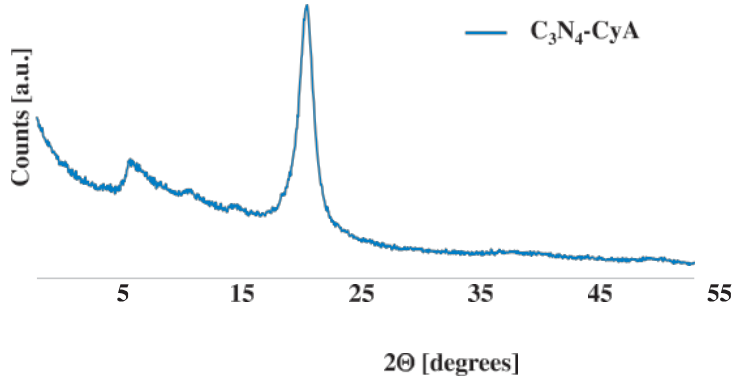

Fig. 1 

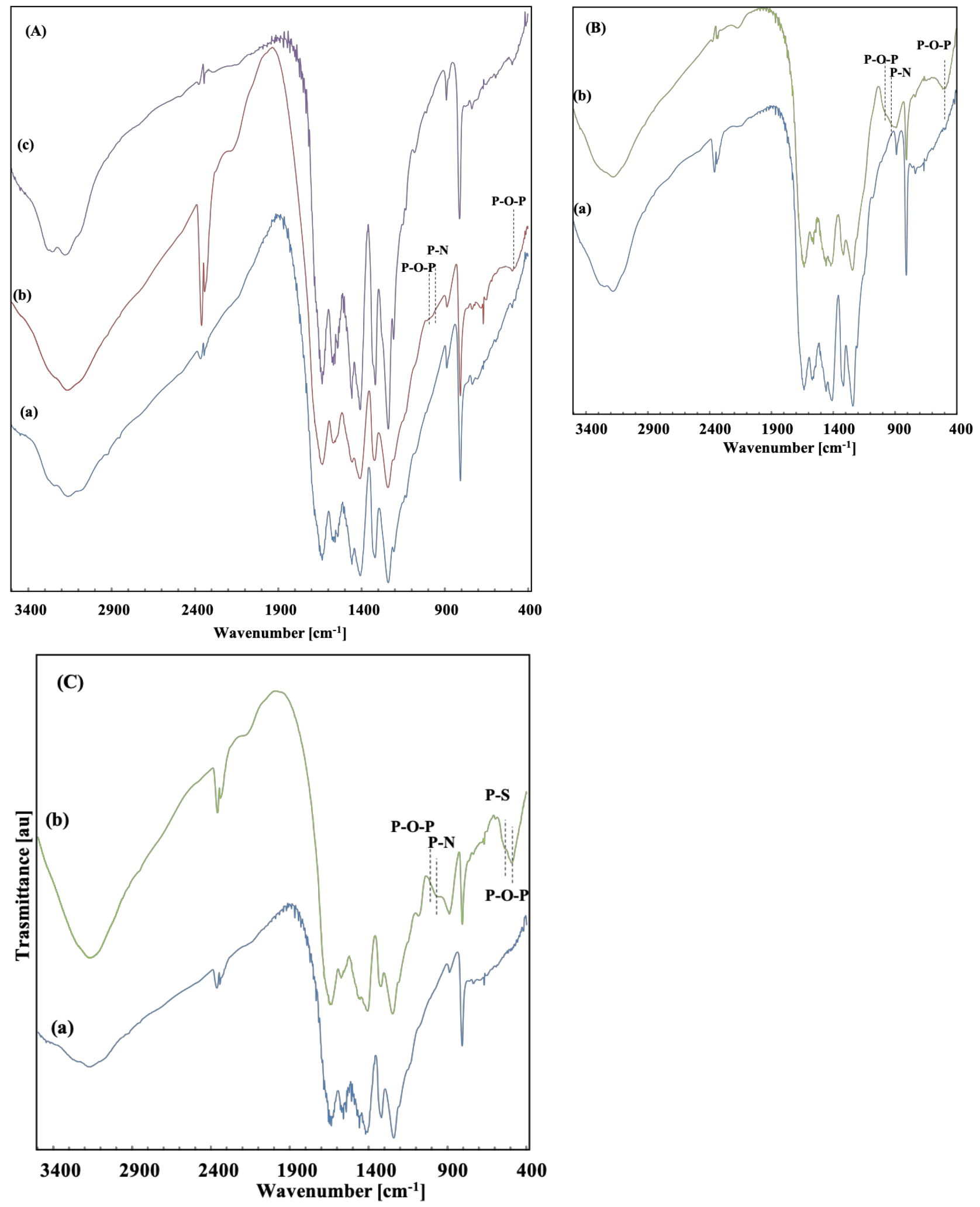

Fig. 2 

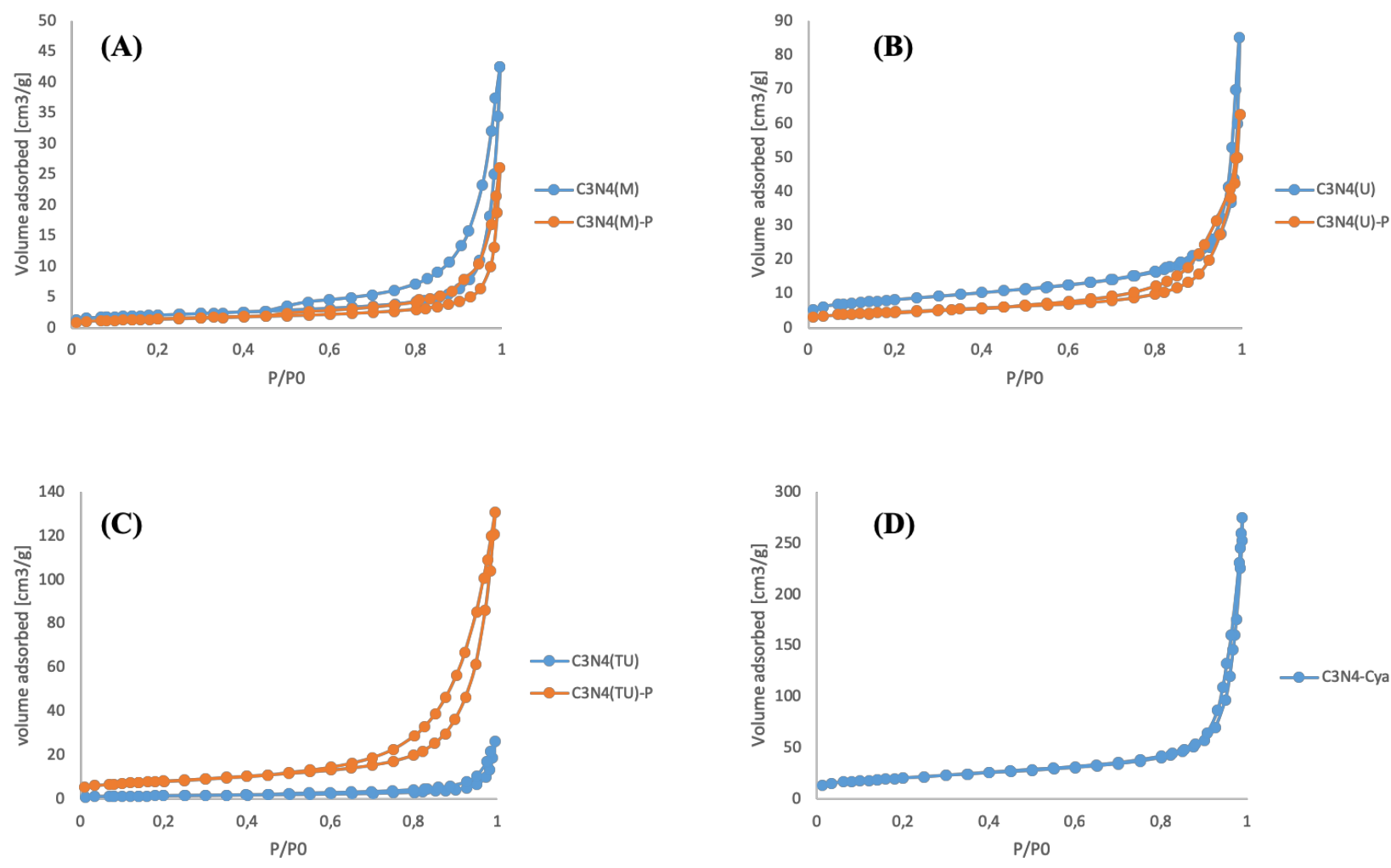

Fig. 3 

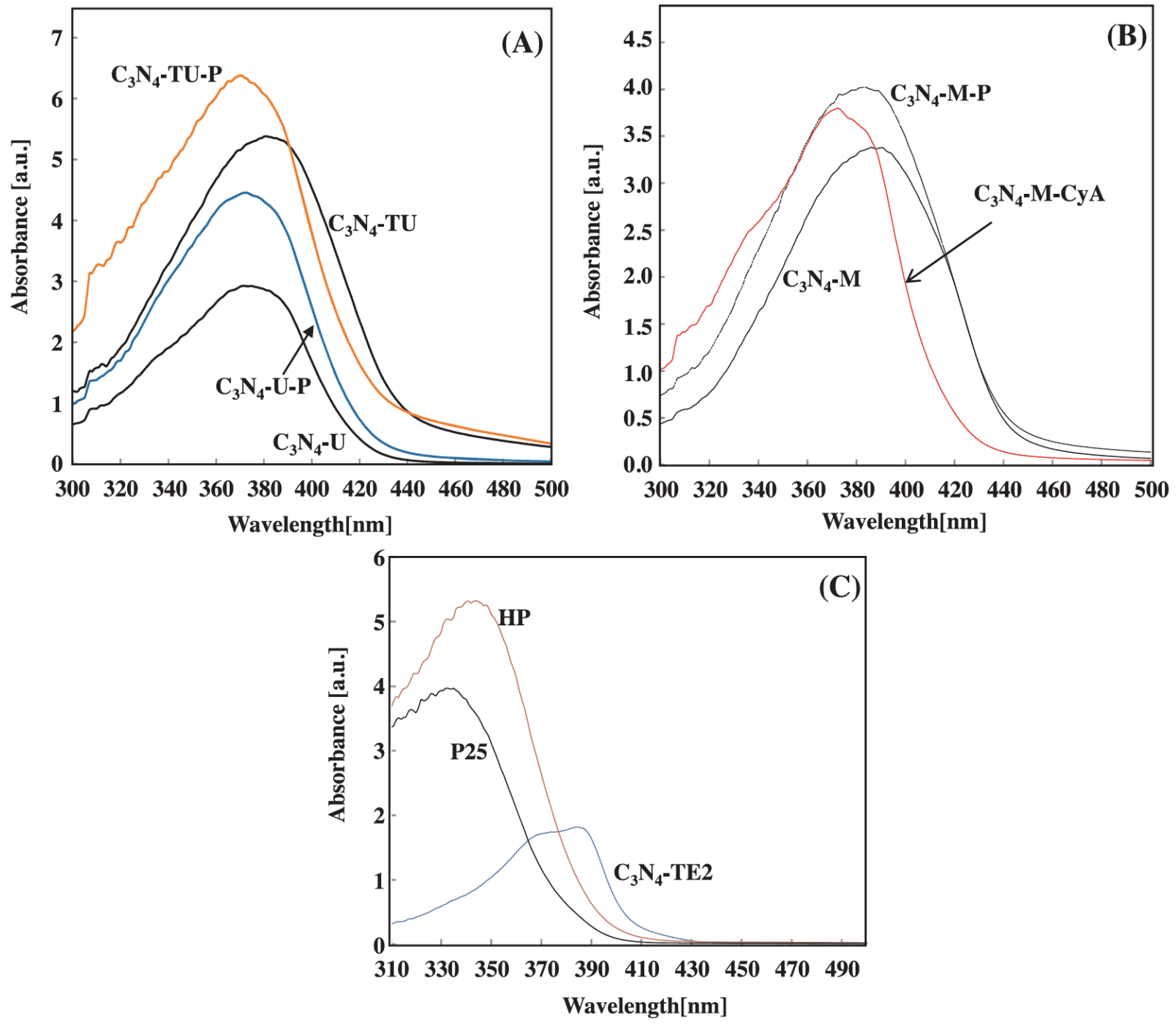

Fig. 4 

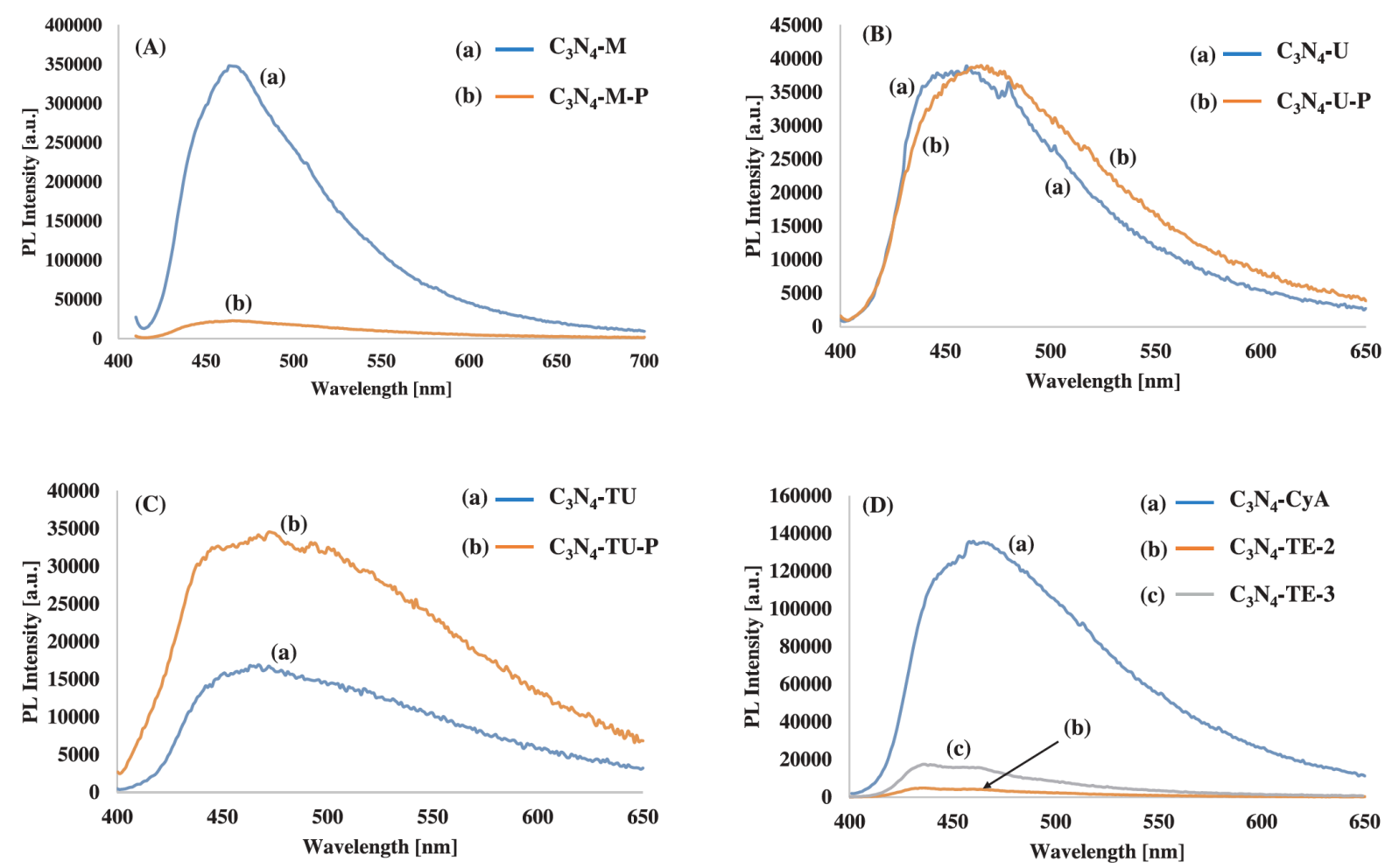

Fig. 5
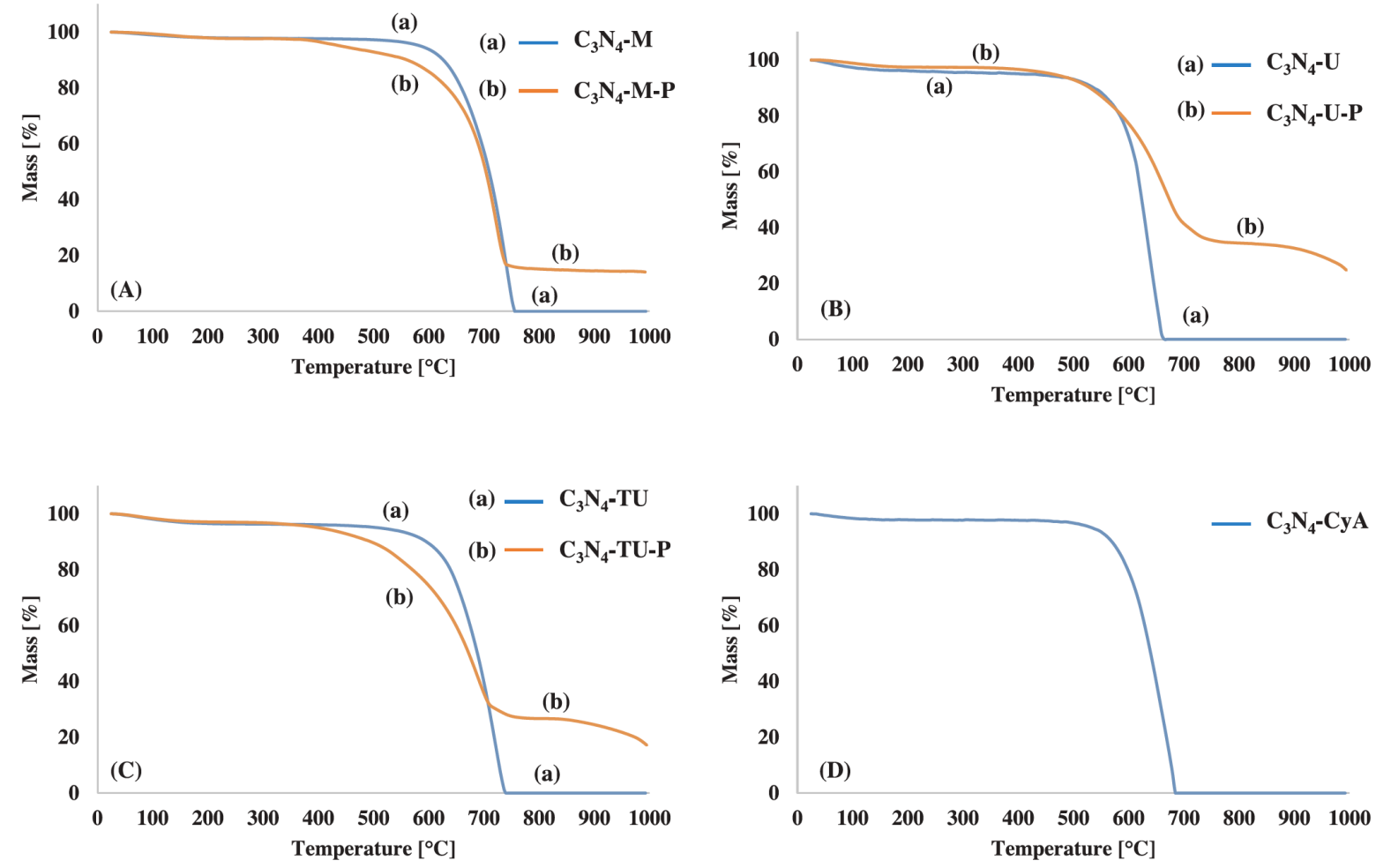

Fig. 6 

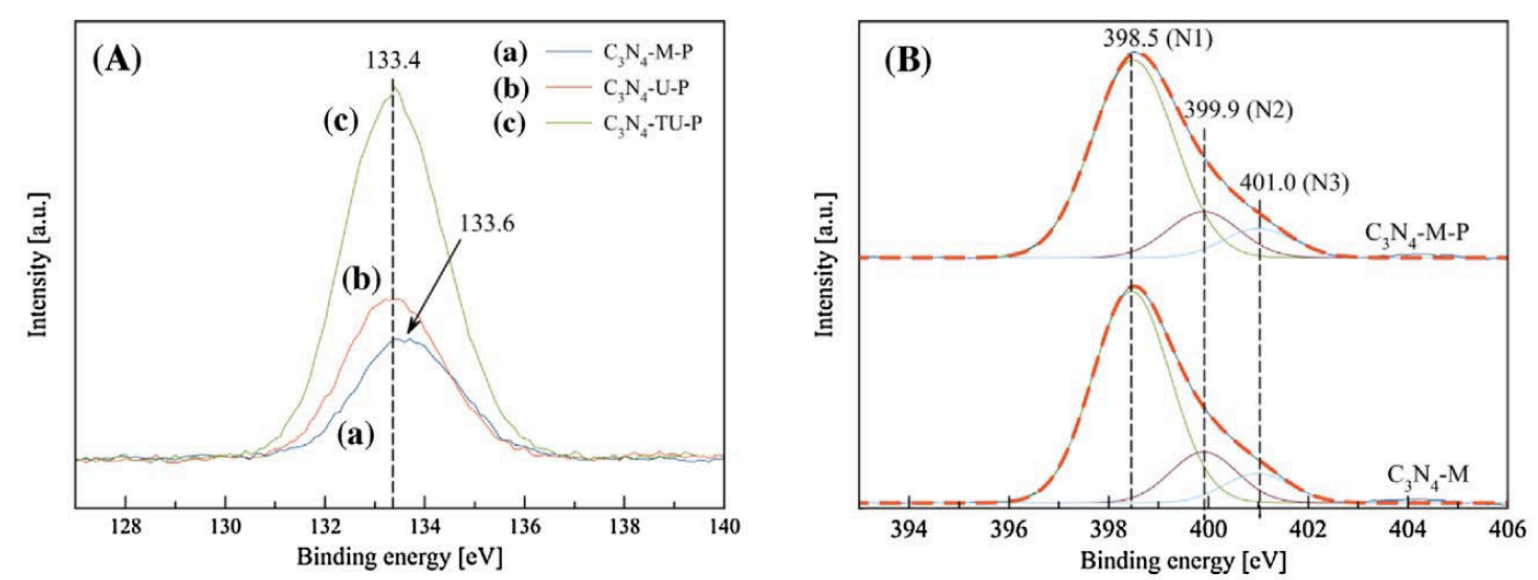

离
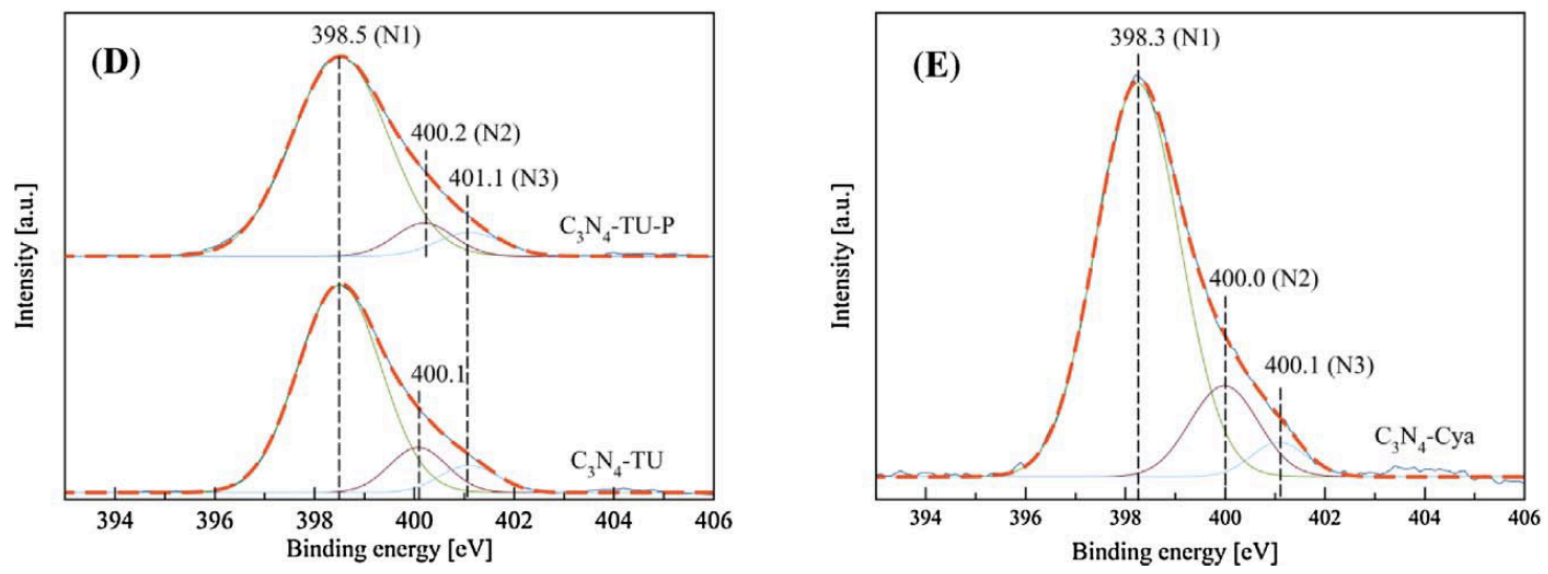

Fig. 7 

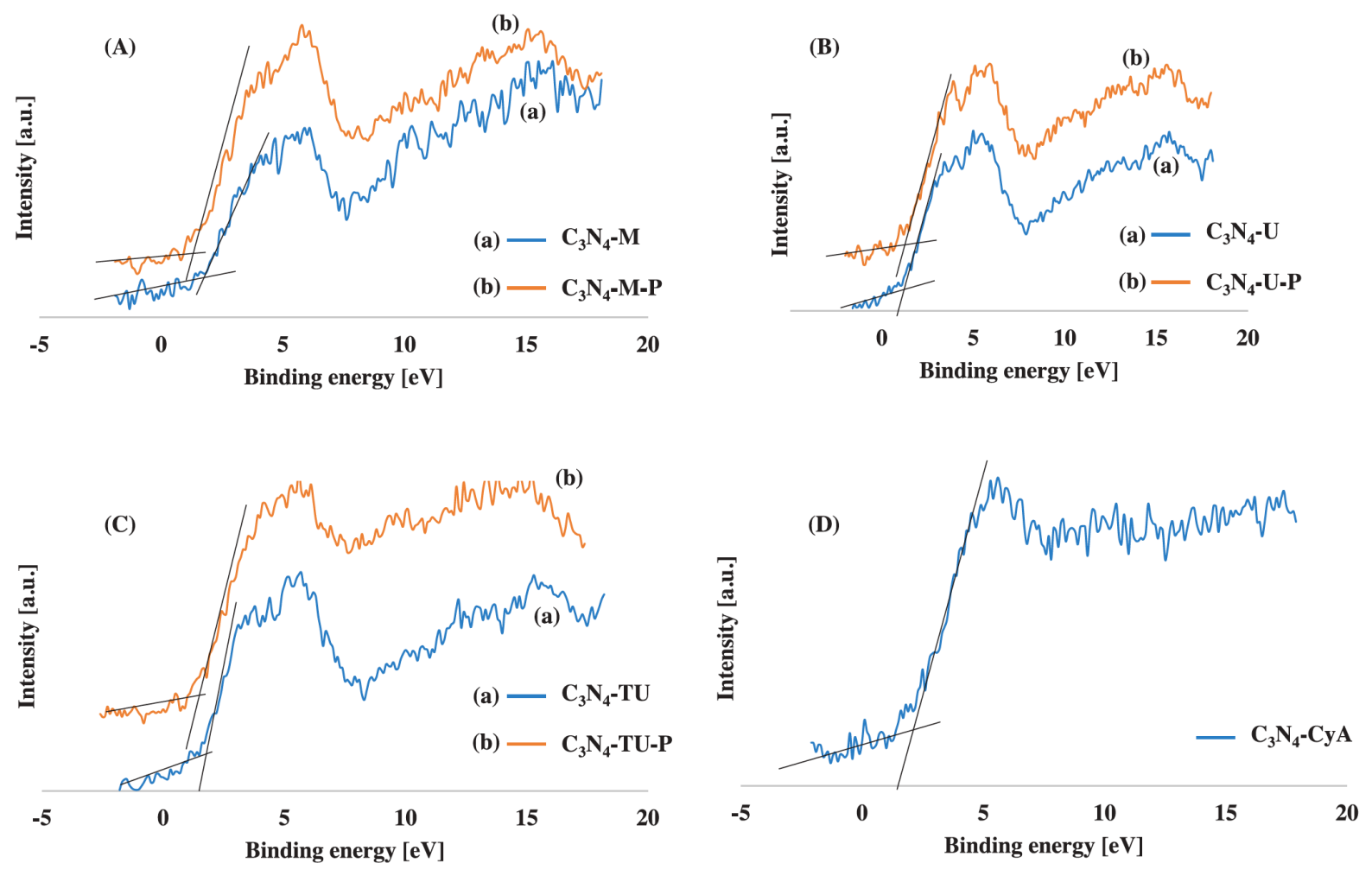

Fig. 8
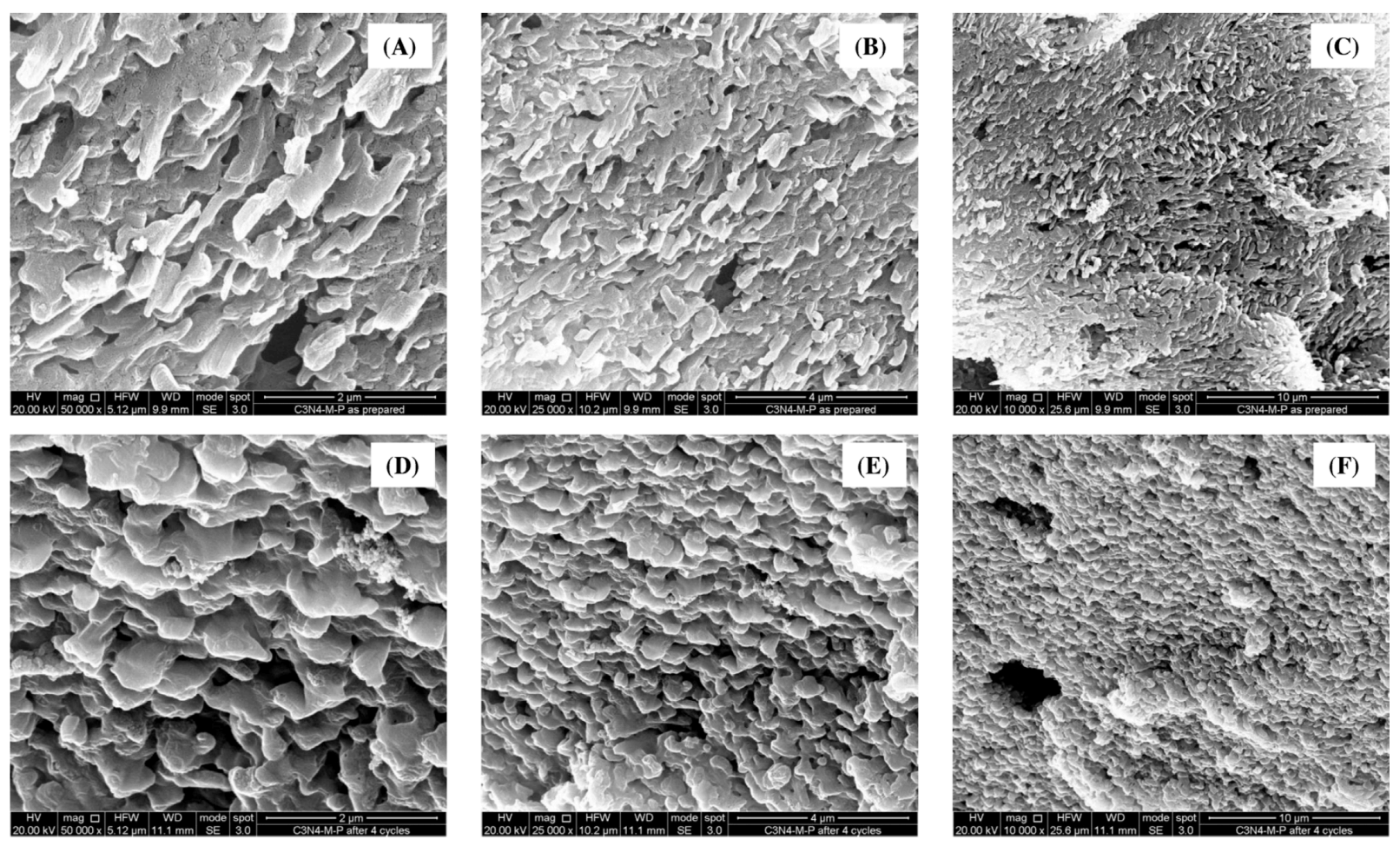

Fig. 9 